\title{
Inactivation of Bacteria by Non-Thermal Plasmas
}

\author{
R. Morent and N. De Geyter \\ Research Unit Plasma Technology - Department of Applied Physics \\ Faculty of Engineering and Architecture - Ghent University \\ Belgium
}

\section{Introduction}

In physical sciences, "plasma" refers to the forth state of matter, while in medicine and biology, plasma is known as the non-cellular component of blood (Fridman et al., 2008). Interestingly, the term "plasma" has been coined by Irving Langmuir to emphasize that the characteristics of ionic liquids ubiquitous in biology and medicine are analogous to plasma in the physical sciences (Fridman et al., 2008, Langmuir, 1928). Despite this historical connection, plasmas are mainly associated with the solid-state processing technology (Stoffels et al., 2003), while being rarely used in biomedical applications directly. This situation is however rapidly changing and multiple plasma applications in life sciences are recently emerging (Daeschlein et al., 2010, Vandamme et al., 2010, Kalghatgi et al., 2010, Kong et al., 2009, Nie et al., 2009, Kalghatgi et al., 2007).

The plasma state can be considered to be a gaseous mixture of oppositely-charged particles with a roughly zero net electrical charge (Denes\&Manolache, 2004). Besides charged particles, plasmas also contain neutral atoms and molecules, excited atoms and molecules, radicals and UV photons. Generally, plasmas can be subdivided into 2 categories: thermal plasmas and non-thermal (or cold) plasmas (Denes\&Manolache, 2004, Fridman et al., 2008, Bogaerts et al., 2002). Thermal plasmas are characterized by very high temperatures of electrons and heavy particles, both charged and neutral. In contrast, non-thermal plasmas are composed of low temperature particles (charged and neutral molecular and atomic species) and relatively high temperature electrons (Bogaerts et al., 2002, Denes\&Manolache, 2004). Because the ions and the neutrals remain relatively cold, a non-thermal plasma does not cause any thermal damage to articles it comes in contact with. This characteristic opened up the possibility to use these non-thermal plasmas for the treatment of heat-sensitive materials including biological matter such as cells and tissues (Laroussi, 2009). Non-thermal plasmas are already routinely used in material processing applications, such as etching, activation and deposition (Borcia et al., 2006, Bruce et al., 2010, De Geyter et al., 2008, De Geyter et al., 2009, Morent et al., 2009a, Morent et al., 2009b, Maruyama et al., 2010). More recently, the biological and medical applications of these plasmas have witnessed a great interest from both plasma as well as medical research communities.

This review paper focuses on one specific fascinating application of non-thermal plasmas in biomedical science, namely the inactivation of bacteria, also called plasma sterilization 
(Stoffels et al., 2008). We need to stress that the term sterilization is somewhat ambiguous since this term is only used when all initial micro-organisms are killed, which is however not always the case when applying non-thermal plasmas to contaminated surfaces (Boudam et al., 2006). Conventional sterilization methods include the use of dry heat (oven), moist heat (autoclave) or chemicals like gaseous ethylene oxide, liquid formaldehyde and glutaraldehyde (Kelly-Wintenberg et al., 1998, Moisan et al., 2001, Moisan et al., 2002, Park et al., 2003). Some major drawbacks of these conventional techniques are the high processing temperatures (ovens and autoclaves) which makes it impossible to sterilize heat-sensitive materials like polymers, the use of toxic chemicals and the long sterilization times needed (approximately 12 hours in the case of ethylene oxide exposure) (Park et al., 2003, Moisan et al., 2001, Montie et al., 2000). Another interesting sterilization method is the use of gamma irradiation, but this is an expensive technique and may cause the material to undergo undesirable changes during sterilization (Moisan et al., 2001, Henn et al., 1996, Ishigaki\&Yoshii, 1992). The limitations of these conventional methods have encouraged the search for new approaches and an alternative method of sterilization is treatment with a non-thermal plasma (plasma sterilization). These plasmas operate under moderate temperatures and use non-toxic gases, therefore, thermal and chemical damage to the substrate is limited (Philip et al., 2002, Sladek\&Stoffels, 2005). Moreover, plasmas are not only capable of killing bacteria and viruses, they can also remove these dead microorganisms from the surfaces of the objects being sterilized (Chau et al., 1996). This chapter on plasma sterilization is organized as follows: a first part will focus on the inactivation of bacteria on non-living surfaces, which has reached a state of maturity. In this first section, the kinetics of bacterial inactivation processes will be described, followed by the effects of various plasma-generated agents on bacterial cells. Afterwards, a brief review on the inactivation of bacteria on non-living surfaces by vacuum and atmospheric pressure plasmas will be presented. A second part of the chapter will deal with state-of-the-art applications of non-thermal plasmas in bacterial inactivation, namely the sterilization of teeth and human/animal tissue, which are both relatively new research topics.

\section{Plasma sterilization on non-living surfaces}

\subsection{Survival curves to determine the inactivation efficiency}

Plasma effects on micro-organisms can be evaluated using various methods, however, a commonly used approach is the determination of survival curves (Stoffels et al., 2008, Boudam et al., 2006, Moisan et al., 2002). These curves are plots of the logarithm of the number of surviving micro-organisms as a function of exposure time to the sterilizing agent. Although the precise procedures to obtain these curves may vary, usually a suspension containing a well-defined concentration of micro-organisms is placed on a substrate and let to dry. After plasma exposure, the remaining micro-organisms are let to inoculate for several hours before counting. Considering that counting large numbers of cells is troublesome, the number of colony forming units (CFU) is determined instead of counting individual cells after inoculation (Stoffels et al., 2008). For conventional sterilization methods, the survival curve is usually a unique straight line: the inactivation process is an exponential function of time (Moisan et al., 2002, Cariou-Travers\&Darbord, 2001). In contrast, plasma sterilization can provide survival curves with different shapes depending on the type of micro-organism, the type of medium supporting the micro-organisms and the method of plasma exposure (direct or remote) (Laroussi et al., 2000, Laroussi, 2002). In some 
cases, the survival curves after plasma exposure are straight lines (similar to conventional sterilization methods) (Laroussi et al., 2000, Herrmann et al., 1999, Yamamoto et al., 2001), however, in most cases, two or even three different linear segments occur, each segment being a different inactivation phase (Kelly-Wintenberg et al., 1998, Moisan et al., 2002, Laroussi et al., 2000). This implies that the number of surviving micro-organisms is also an exponential function of time, but with different time constants. To characterize the slope of each segment, an interesting parameter has been extensively used by several researchers studying plasma sterilization: the so-called "D-value" (decimal value) (Moisan et al., 2002, Laroussi, 2002, Fridman, 2008). This parameter is the time required to reduce an original concentration of micro-organisms by $90 \%$ (one $\log _{10}$ reduction) and is expressed in the unit of time.

Single-slope survival curves have been observed in atmospheric pressure plasma sterilization by Herrmann et al. (Herrmann et al., 1999), Laroussi et al. (Laroussi et al., 2000) and Yamamoto et al. (Yamamoto et al., 2001) and an example of such a single-slope curve is presented in Figure 1.

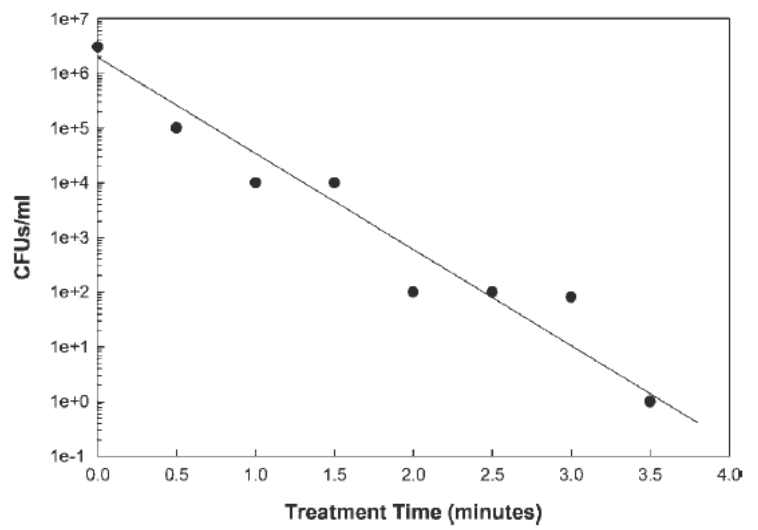

Fig. 1. Example of a single-slope survival curve: E.coli exposed to an atmospheric pressure glow discharge in a helium/air mixture [Reprinted with permission from (Laroussi, 2005)].

Herrmann et al. (Herrmann et al., 1999) employed a remote atmospheric pressure plasma jet in a helium/oxygen mixture to treat Bacillus globigii spores on glass coupons and found a D-value of 4.5 seconds. Laroussi et al. (Laroussi et al., 2000) and Yamamoto et al. (Yamamoto et al., 2001) utilized an atmospheric pressure glow discharge (DBD) in a helium/air mixture and an argon $/ \mathrm{H}_{2} \mathrm{O}_{2}$ corona discharge respectively to treat Escherichia coliphage (E. coli). In these studies, single-slope survival curves were reported with D-values ranging from 15 seconds for the corona discharge to 5 minutes for the DBD-discharge (Laroussi et al., 2000, Laroussi, 2002, Yamamoto et al., 2001). More recently, Stoffels et al. (Sladek\&Stoffels, 2005, Stoffels et al., 2008) and Choi et al. (Choi et al., 2006) presented results on plasma-induced deactivation of $E$. coli using a plasma needle operating in helium/air mixtures and a dielectric barrier discharge (DBD) in air respectively and also found a straight line as survival curve.

Two-slope survival curves can occur in both vacuum and atmospheric pressure plasma sterilization and were observed for the first time in 1998 by Hury et al. (Hury et al., 1998). These authors reported on the inactivation of different Bacillus spores in an oxygen plasma 
operating at low pressure $(0.5 \mathrm{~Pa})$ and did not observe a linear survival curve, but two successive lines with different slopes. According to their findings, the first slope has the smallest D-value $\left(D_{1}\right)$, while the D-value of the second slope $\left(D_{2}\right)$ is larger. As a result, the authors concluded that the inactivation of spores in their low pressure oxygen plasma is a two-step process: a fast process followed by a much slower one. Similar two-slope curves, as illustrated in Figure 2, were found in 2000 and 2002 by Moreau et al. (Moreau et al., 2000) and Philip et al. (Philip et al., 2002), who employed low pressure (133-933 Pa) microwave discharges in pure argon and $\mathrm{N}_{2} / \mathrm{O}_{2}$ mixtures ( $7 \%$ oxygen) respectively for the inactivation of Bacillus subtilis spores. According to both Hury (Hury et al., 1998) and Moreau (Moreau et al., 2000), the first phase of their survival curve corresponds to the action of UV irradiation on isolated spores or on the first layers of stacked spores. The second phase, which is characterized by slower kinetics, represents spores that are shielded by others and thus require longer irradiation times to accumulate a lethal UV dose.

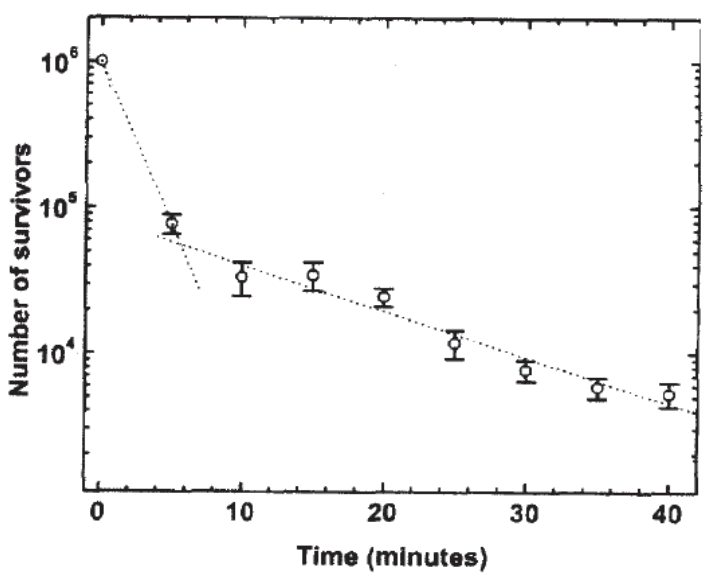

Fig. 2. Evolution as a function of time of the population of spores submitted to a pure argon afterglow at low pressure [Reprinted with permission from (Moreau et al., 2000)].

As previously mentioned, two-slope survival curves have also been observed in atmospheric pressure plasmas. Kelly-Wintenberg et al. (Kelly-Wintenberg et al., 1998) and Laroussi et al. (Laroussi et al., 2000) employed an atmospheric pressure glow discharge (DBD) for the inactivation of E. coli, Staphylococcus aureus and Pseudomonas aeruginosa. In contrast to the vacuum plasmas, the D-value of the observed second slope $\left(D_{2}\right)$ was smaller than the D-value of the first slope $\left(D_{1}\right)$ in these plasma systems. A general example of the observed survival curves is shown in Figure 3.

Montie et al. (Montie et al., 2000) found similar survival curves for the inactivation of $E$. coli and $B$. subtilis on glass, polypropylene and agar and claimed that the $\mathrm{D}_{1}$-value depends on the species being treated, while the $\mathrm{D}_{2}$-value depends on the type of surface supporting the micro-organisms (Laroussi, 2002, Fridman, 2008). A hypothesis for the two-slope survival curve was given by Kelly-Wintenberg et al. (Kelly-Wintenberg et al., 1998): during the first killing stage, active plasma species react with the outer membrane of the cells leading to damaging alterations. After this process has sufficiently advanced, the reactive species can quickly cause cell death, resulting in a very rapid second phase. 


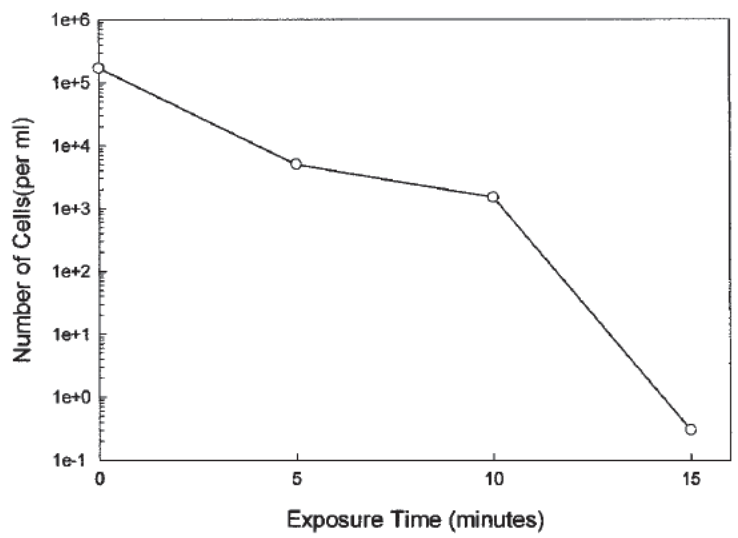

Fig. 3. Survival curve of Pseudomonas aeruginosa exposed to an atmospheric pressure glow discharge in a helium/air mixture [Reprinted with permission from (Laroussi et al., 2000)].

Multi-slope survival curves with three (or more) linear segments have also been observed in both vacuum as well as atmospheric pressure plasma sterilization. Moreau et al. (Moreau et al., 2000), Moisan et al. (Moisan et al., 2002) and Philip et al. (Philip et al., 2002) found three inactivation phases when employing a low pressure (133-933 Pa) microwave discharge in argon/oxygen and $\mathrm{N}_{2} / \mathrm{O}_{2}$ mixtures (0.7-2 \% oxygen) respectively for the inactivation of $B$. subtilis. These authors claim that the first phase, which has the shortest D-value, is mainly due to the action of UV photons on isolated spores or on the first layers of stacked spores. The second phase (with the slowest kinetics) can be attributed to the erosion of the spores by active species, such as atomic oxygen. The third phase starts when the spores that were not inactivated during phases 1 and 2 have been sufficiently eroded, hence allowing UV photons to hit the genetic material of the still-living spores and finally kill them. A schematic illustration of the three-phase survival curve can be found in Figure 4.

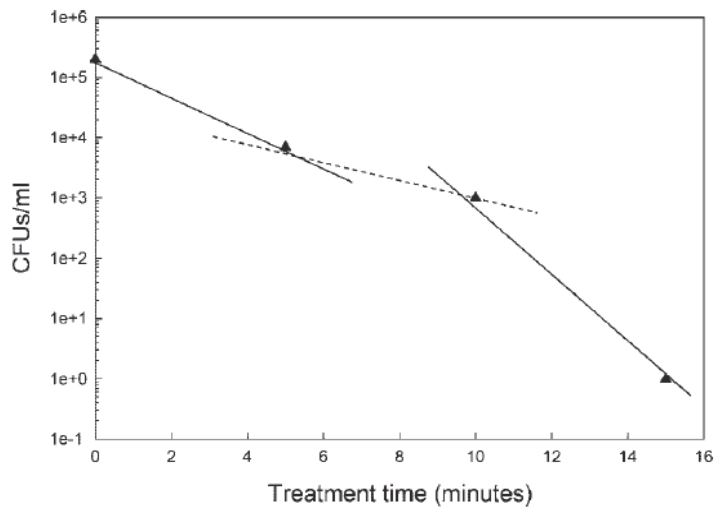

Fig. 4. Example of a three-phase survival curve: inactivation of Pseudomonas aeruginosa with an atmospheric pressure glow discharge in a helium/air mixture [Reprinted with permission from (Laroussi, 2005)]. 
These multi-slope survival curves were also recorded by Laroussi et al. (Laroussi et al., 2000) and Roth et al. (Roth et al., 2000) who employed atmospheric pressure plasma sources for sterilization, however, a clear elucidation for this type of survival curve is lacking for the moment. The explanation given earlier for low pressure plasma sterilization is most likely not applicable to atmospheric pressure plasmas, for which it has been shown that UV photons only play a secondary role in the killing process (Herrmann et al., 1999, Yamamoto et al., 2001, Kostov et al., 2010, Laroussi, 1996). Based on the above-mentioned bacterial inactivation kinetics, one can conclude that the mechanisms of sterilization by both vacuum and atmospheric pressure plasmas are very complex and far from understood at this moment.

\subsection{Plasma species responsible for sterilization}

As mentioned at the end of the previous section, plasma sterilization is a complex process since multiple plasma species, such as UV photons, excited species, reactive neutrals,... can interact with the bacterial cells being treated. This section tries to give an overview of the contributions of various plasma agents (heat, UV radiation, charged particles and reactive species) to the sterilization process.

\subsubsection{Effect of heat}

The first factor that usually comes to mind when discussing sterilization is the effect of heat. As previously mentioned, conventional sterilization methods are based on the use of either dry or moist heat. Moist heat (or autoclaving) is widely used for sterilization by subjecting objects to steam under pressure at temperatures of at least $120^{\circ} \mathrm{C}$ for 15 minutes or longer (Gopal, 1978, Ratner et al., 1990). Dry heat sterilization requires even higher temperatures (close to $170^{\circ} \mathrm{C}$ ) with treatment times of about one hour (Laroussi, 2005). Most non-thermal plasmas operate at low temperatures (room temperature to approximately $70^{\circ} \mathrm{C}$ ), therefore, no substantial thermal effects on bacterial cells are expected in plasma sterilization processes (Laroussi\&Leipold, 2004). However, it should be noted that some non-thermal plasmas (like gliding arc discharges and dielectric barrier discharges) can be characterized by elevated temperatures in localized intervals in space or in time and for these discharges thermal effects should be sometimes also taken into account (Fridman, 2008). However, in general, heat is not a major contributor to the sterilization effect in non-thermal plasmas.

\subsubsection{Effect of UV radiation}

Non-thermal plasmas are a source of UV with different wavelengths, however, only UV radiation in the 200-300 $\mathrm{nm}$ wavelength range with doses of several $\mathrm{mJ} / \mathrm{cm}^{2}$ are known to cause lethal damage to cells (Fridman, 2008, Laroussi, 2005). This damage is mainly the dimerization of thymine bases in bacterial DNA strands, which inhibits the ability of bacteria to replicate properly (Fridman, 2008, Laroussi, 2005).

The presence of UV radiation in the plasma strongly depends on the operating pressure. It is well-known that vacuum plasma discharges are able to provide significant UV radiation in the range of wavelengths effective in sterilization. This can explain the important contribution of UV radiation in plasma sterilization at low pressures, as discussed in the previous section. In contrast, the great majority of papers published on the inactivation of micro-organisms by atmospheric pressure plasmas conclude that the contribution of UV radiation to the inactivation process is not important, when not at all relevant. By comparing 
the killing kinetics of UV radiation from a low pressure mercury-vapour lamp with that of a glow discharge plasma at atmospheric pressure, Laroussi et al. (Laroussi, 1996) concluded in 1996 that UV was not the main killing agent. In 1998, this claim was supported by KellyWintenberg et al. (Kelly-Wintenberg et al., 1998) who exposed different types of microorganisms to an atmospheric pressure glow DBD in air. These authors observed that there is no significant difference in the time needed to inactivate micro-organisms on polypropylene samples, whether exposed directly or sealed in bags. They concluded from this observation that UV is not a significant contributor to lethality since the opaque bags would have blocked much of the UV light (Kelly-Wintenberg et al., 1998). In the following years, several researchers (Laroussi, 2002, Laroussi, 2005, Choi et al., 2006, Laroussi\&Leipold, 2004, Birmingham, 2004) have carried out various experiments that also supported the claim that UV plays a minor role in plasma sterilization. In 1999, Herrmann et al. (Herrmann et al., 1999) exposed Bacillus globigii to a remote atmospheric pressure plasma jet operating in helium/oxygen mixtures. When the reactive plasma effluent was blocked by a quartz window, allowing only UV radiation and heat to reach the spores, no substantial reduction in the initial concentration of bacteria was observed. In 2004, Laroussi and Leipold (Laroussi\&Leipold, 2004) used the flowing afterglow of a DBD in air at atmospheric pressure to inactivate spores of the Bacillus genus. They quantified the UV emission from the discharge and observed no significant UV emission in the wavelength range effective in sterilization. Also in 2004, Birmingham (Birmingham, 2004) tested what he calls a "plasma blanket", which is an aluminium foil layer covered by a micro-machined dielectric polyimide layer. This structure provides small corona discharge spots in air and can be wrapped around a contaminated object. The author states that the "plasma blanket" does not generate sufficient photons of the appropriate wavelength and thus concludes that the inactivation process only results from the interaction of the ionized gas with the biological material. Choi et al. (Choi et al., 2006) subjected different samples to a DBD operated in air at atmospheric pressure and found no UV radiation below $290 \mathrm{~nm}$. As a result, they concluded that UV plays no significant role in plasma sterilization. In an interesting review paper, Laroussi et al. (Laroussi, 2005) specifically concluded that there is no UV radiation in the 200-285 nm wavelength for dry air non-thermal plasmas at atmospheric pressure. Therefore, UV photons are not likely to take part in the inactivation of micro-organisms when air plasmas are used.

In contrast to the previous literature overview, some authors (Park et al., 2003, Heise et al., 2004, Lee et al., 2005, Trompeter et al., 2002) do mention the possible role of UV photons in plasma sterilization at atmospheric pressure, however, the arguments brought forward are quite often not fully convincing or incomplete (Boudam et al., 2006). For example, Trompeter et al. (Trompeter et al., 2002) employed an atmospheric pressure filamentary DBD in different gases and found that argon was the most efficient gas in terms of spore inactivation. As a result, they concluded that the inactivation process is purely due to UV radiation since argon is chemically inactive. Heise et al. (Heise et al., 2004) employed a similar discharge in argon and claimed that the inactivation of spores is partly due to UVinduced effects. Both Trompeter et al. (Trompeter et al., 2002) and Heise et al. (Heise et al., 2004) present their results as being performed in pure argon, nonetheless this is not the case since impurities are always present in the discharge gas (Boudam et al., 2006). This contamination can strongly reduce the UV emission (Boudam et al., 2006), therefore, the role of UV in the inactivation process might not be as large as mentioned by these authors. Recently, Boudam et al. (Boudam et al., 2006) subjected micro-organisms to an atmospheric 
pressure DBD operated in an $\mathrm{N}_{2} / \mathrm{N}_{2} \mathrm{O}_{2}$ mixture. These authors claim that they have proven that UV photons, under specific operating conditions, can be the dominant inactivation species. The role of UV in atmospheric pressure plasma sterilization is thus still open for debate and further research should be definitely conducted before the controversy can be resolved.

\subsubsection{Effect of reactive species}

According to several authors (Laroussi, 2002, Laroussi, 2005, Fridman, 2008), reactive neutral species (such as $\mathrm{O}, \mathrm{O}_{2}{ }^{*}, \mathrm{O}_{3}, \mathrm{OH}^{*}, \mathrm{NO}$ and $\mathrm{NO}_{2}$ ) can make a significant contribution to the plasma sterilization process, especially at high pressures. To show the effect of these reactive species on the destruction of bacteria, Laroussi and Leipold (Laroussi\&Leipold, 2004) employed an atmospheric pressure DBD in three different gases: pure helium, 97\% helium-3\% oxygen mixture and air to inactivate Bacillus spores. When helium is used as discharge gas, only very small concentrations of radicals originating from impurities are expected. When helium is mixed with oxygen, oxygen-based species such as $\mathrm{O}$ and $\mathrm{O}_{3}$ will be present in the discharge. When air is used as discharge gas, both oxygen- and nitrogenbased species will be generated. Figure 5 shows a comparison between the inactivation kinetics in the case of pure helium and the helium/oxygen mixture.

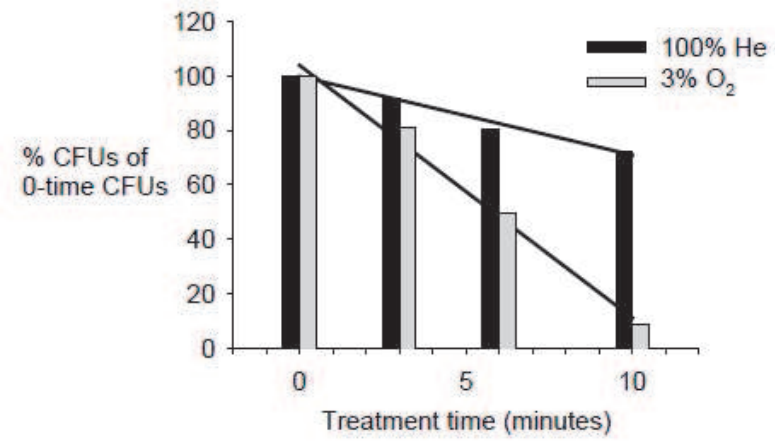

Fig. 5. Percent of surviving Bacillus spores as a function of plasma treatment time for pure helium (black) and a helium/oxygen mixture $\left(97 \% \mathrm{He}-3 \% \mathrm{O}_{2}\right)$ (gray) [Reprinted with permission from (Laroussi\&Leipold, 2004)].

When pure helium was used as discharge gas, the surviving spore population percentage was still much greater than $10 \%$ after 10 minutes of plasma treatment. In fact, in this case, the D-value was greater than 20 minutes. When a helium/oxygen mixture was employed, as shown in Figure 5, a D-value of 10 minutes was achieved. Laroussi and Leipold (Laroussi\&Leipold, 2004) also showed that in the case of an air plasmas, the D-value could be even further decreased to approximately 20 seconds. According to these authors, this dramatic decrease in inactivation efficacy can thus be attributed to the presence of chemically reactive species such as $\mathrm{NO}, \mathrm{NO}_{2}, \mathrm{O}, \mathrm{O}_{3}, \ldots$ Besides Laroussi and Leipold, other authors (Herrmann et al., 1999, Moreau et al., 2000, Richardson et al., 2000) have also experimentally shown that discharges containing oxygen provide a strong germicidal effect. In particular, Herrmann et al. (Herrmann et al., 1999) compared results obtained by an atmospheric pressure plasma jet with and without oxygen. These authors found that the D- 
value in the case of absence of oxygen is higher than in the case when oxygen is added. Richardson et al. (Richardson et al., 2000) also showed that their resistive barrier discharge became more effective in killing $B$. subtilis when oxygen was added to the discharge gas helium. It is believed that the oxygen species attribute to the sterilization process due to their strong oxidative effects on the outer structures of cells (Fridman, 2008). Moreover, discharges containing oxygen also generate ozone $\left(\mathrm{O}_{3}\right)$ which interferes with the cellular respiration system and is known to have a strong bactericidal effect (Laroussi, 2002). After experimenting with different gas mixtures, Kuzmichev et al. (Kuzmichev et al., 2000) concluded that the best bactericidal effects were achieved in moistened oxygen and air. In the presence of moisture, hydroxyl $(\mathrm{OH})$ radicals are generated in the plasma, which play a significant role by chemically attacking the outer structures of bacterial cells. In the case of air, the production of $\mathrm{NO}$ and $\mathrm{NO}_{2}$ adds to the lethality of the process.

\subsubsection{Effect of charged particles}

In the discussion of the mechanisms of inactivation, a lot of attention is given to the effect of $\mathrm{UV}$ radiation and reactive species and most researchers have neglected to investigate the influence (if any) of charged particles. As a result, the exact role of electrons and ions is not yet fully resolved, but there are several indications of their importance. Fridman et al. (Fridman et al., 2007, Fridman, 2008) have stated that charged particles play an essential role in sterilization, especially in the case of direct plasma treatment, i.e. when the plasma is in direct contact with the micro-organisms. These authors employed an atmospheric pressure air DBD in direct mode and afterglow mode (so-called "plasma jet") at similar discharge powers and with the same amount of UV radiation and the results comparing the direct and indirect effects of plasma sterilization are illustrated in Figure 6. From this figure, it can be clearly seen that direct application of plasma yields a better sterilization efficiency than the treatment by plasma afterglow. Although this high efficiency in the direct mode cannot be solely described to the role of charged particles (the concentration of reactive species is also lower in case of indirect exposure), it could be possible that charged-induced mechanisms contribute to the sterilization process in direct plasma exposure.
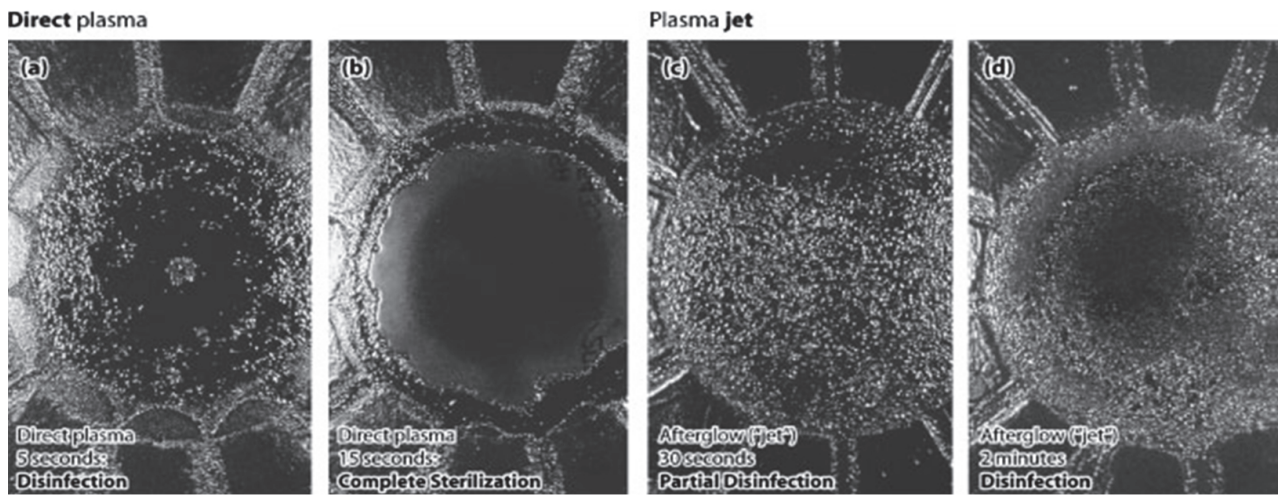

Fig. 6. Effect of direct application of plasma (a: 5 seconds, b: 15 seconds) and effect of plasma afterglow (c: 30 seconds, d: 2 minutes) [Reprinted with permission from (Fridman et al., 2007)]. 
Mendis et al. (Mendis et al., 2000) also suggested that charged particles might play a significant role in the rupture of outer cell membranes. According to these authors, charge accumulation on the outer surface of the membrane induces an electrostatic force, which can overcome the tensile strength of the membrane causing its rupture. They also state that this mechanism is only effective for Gram-negative bacteria, which posses thin outer membranes and a thin murein layer. The scenario will probably not occur for Gram-positive bacteria, which lack an outer membrane but have a much thicker murein layer thereby providing these bacteria higher strength and rigidity. Their conclusions can be supported by several experimental observations. Kelly-Wintenberg et al. (Kelly-Wintenberg et al., 1999) employed an atmospheric pressure glow discharge for the inactivation of the Gram-negative E. coli and used transmission electron microscopy (TEM) to visualize the plasma-induced physical damage to the micro-organisms. Figures 7 (a) and (b) show the cells before plasma exposure and after 30 seconds of plasma treatment respectively. As observed in these figures, plasma exposure rapidly disrupts the cell wall and leads to a release of cellular contents in the surrounding medium. Laroussi et al. (Laroussi, 2002) employed a similar discharge for the inactivation of the Gram-positive B. Subtilis and found intact cell walls after plasma sterilization, which clearly supports the claim of Mendis et al.. Based on the abovementioned discussion, one can conclude that there may be a contribution of charged particles in bacterial inactivation, but most likely only in direct plasma treatment, however, this interesting possibility remains to be investigated in detail.

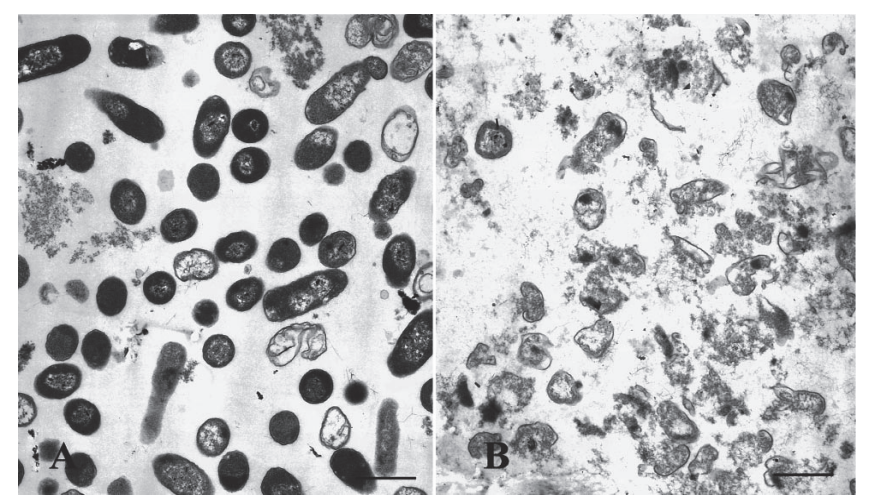

Fig. 7. TEM images of E. coli (A) before and (B) after 30 seconds of plasma exposure [Reprinted with permission from (Kelly-Wintenberg et al., 1999)].

\subsection{Vacuum plasmas}

Glow discharge plasmas operated in vacuum have been successfully employed to sterilize surfaces for quite some time. Patents written by Ashman and Menashi (Ashman\&Menashi, 1972) as well as by Gut Boucher (Gut Boucher, 1980) showed that an electrical discharge in an appropriate gas can lead to sterilization. In these patents, samples are inserted within a chamber which is subsequently evacuated with a pump to 1-5 Pa. Afterwards, this chamber is filled with gas set at the required pressure, typically 5-300 $\mathrm{Pa}$. The gas discharge is then achieved by applying an RF field to the gas by means of a coil located on the outside of the chamber. Ashman and Menashi (Ashman\&Menashi, 1972) used different discharge gases, such as chlorine, bromine, iodine, water vapour, oxygen and nitrogen, but only observed an 
effective sterilizing effect when halogens were used as discharge gas. Gut Boucher (Gut Boucher, 1980) added aldehyde vapours to different carrier gases (oxygen, argon or nitrogen) and observed the best results with oxygen as carrier gas. In 1987, Jacobs and Lin (Jacobs\&Lin, 1987) employed a similar RF discharge in a two-step process: (1) injection and contact of hydrogen peroxide $\left(\mathrm{H}_{2} \mathrm{O}_{2}\right)$ with the item being sterilized; (2) application of an RF discharge to ensure that no toxic residues remain on the sterilized item. It is however important to note that the previously mentioned systems are not really plasma-based sterilization systems due to the use of gas mixtures that contain components with germicidal properties (such as $\mathrm{H}_{2} \mathrm{O}_{2}$ and aldehydes) before the plasma is ignited (Laroussi, 2005). Nevertheless, some of these sterilization systems have been commercially available since the 1990s (Montie et al., 2000, Rutala et al., 1998, Vassal et al., 1998).

One of the first reports on plasma sterilization where gases were used with no germicidal properties on their own was published in 1976 by Fraser et al. (Fraser et al., 1976). These authors employed a low pressure RF discharge in different gases (argon, nitrogen, oxygen, helium,...) and obtained reductions in spore populations of $99 \%$ after 2 minutes of plasma exposure. However, it was not specified for which discharge gas this result was obtained. A few years later, in 1982, Bithell (Bithell, 1982) observed that articles placed in a porous envelope could be sterilized in a low pressure $(40 \mathrm{~Pa})$ oxygen RF plasma after a plasma exposure time of 60 minutes. In 1989, Nelson and Berger (Nelson\&Berger, 1989) also claimed that an oxygen RF plasma is very effective as biocidal medium.

Different authors have examined which discharge gas would be the most efficient to inactivate bacterial spores. Hury et al. (Hury et al., 1998) compared the mortality of Bacillus subtilis spores after exposure to low pressure argon, oxygen and $\mathrm{CO}_{2}$ plasmas and concluded that oxygen and $\mathrm{CO}_{2}$ plasmas are much more efficient in destroying $B$. subtilis spores than a pure argon plasma, most likely due to the presence of reactive oxygen species. A similar study was performed by Purevdorj et al. (Purevdorj et al., 2003) who used inert gas plasmas, oxygen-based plasmas and various moisturized air plasmas at low pressure for the inactivation of B. pumilus spores. These authors found that spore survival widely varied depending on the composition of the feed gas. In contrast to the results of Hury et al. (Hury et al., 1998), a pure oxygen plasma caused a lower spore mortality that an argon plasma, however, no clear explanation for this observation was given. Experiments also showed that a 50:50\% oxygen-argon mixture leads to a much higher spore mortality, while the highest mortality could be achieved by employing moisturized air. Based on this latter result, the authors claim that the presence of water vapour enhances the inactivation process, most likely because of the generation of $\mathrm{OH}$ radicals.

Taking into account the high efficiency of oxygen-based plasmas, literature on low pressure sterilization has mainly focused on these kind of plasmas, nevertheless, inert gas plasmas are in some cases still employed for bacterial inactivation (Liu\&Chen, 2008, Yang et al., 2009). Recently, many studies (Bol'shakov et al., 2004, Boscariol et al., 2008, Cvelbar et al., 2006, Liu et al., 2008, Nagatsu et al., 2003, Rossi et al., 2008, Singh et al., 2009, Vicoveanu et al., 2008) on the effects of pure oxygen vacuum plasmas on bacteria have been conducted. Bol'shakov et al. (Bol'shakov et al., 2004) published an interesting paper on the use of an oxygen RF plasma for sterilization purposes. The study was carried out for two operational modes: the inductively coupled mode and the capacitively coupled mode and it was found that the inductive mode offers a better efficiency in destroying bacterial cells. Rossi et al. (Rossi et al., 2008) also employed a low pressure oxygen RF discharge for the inactivation of 
B. stearothermophilus. Figure 8 presents scanning electron microscopy (SEM) images of the untreated spores and spores exposed to the oxygen discharge.

As can be seen, the size of the spores is significantly reduced after 2 minutes of plasma treatment. According to the analysis of a statistically relevant number of spores done on the SEM pictures, it was found that in these conditions the mean length of the spores was reduced from 1.73 to $1.35 \mu \mathrm{m}$. Similar results were obtained by Nagatsu et al. (Nagatsu et al., 2003) and Singh et al. (Singh et al., 2009), who employed a low pressure oxygen microwave discharge. They experimentally confirmed that the B. stearothermophilus spores were sterilized after a plasma exposure time of 3 minutes. Moreover, based on SEM images of the spores, these authors found that the sterilized spores had different sizes and shapes compared to the untreated ones, which could be attributed to the interactions with reactive oxygen species.

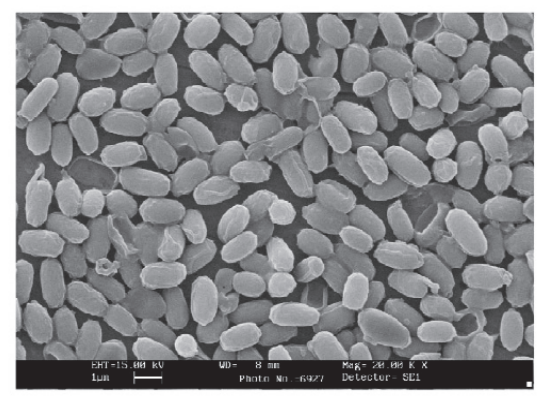

A)

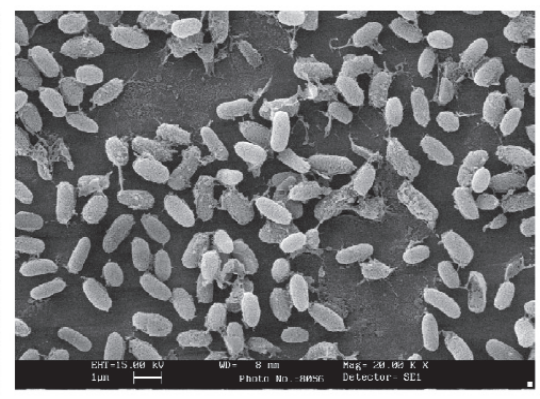

B)

Fig. 8. SEM images of (A) untreated and (B) oxygen plasma-treated spores [Reprinted with permission from (Rossi et al., 2008)].

Pure oxygen plasmas have also been employed by Cvelbar et al. (Cvelbar et al., 2006) and Vicoveanu et al. (Vicoveanu et al., 2008) for the inactivation of B. subtilis spores, who claimed that substrate heating might play a role in the inactivation process, especially at elevated discharge powers. In another study on pure oxygen plasmas, Boscariol et al. (Boscariol et al., 2008) shows the influence of discharge power on the bacterial inactivation of B. subtilis spores. Linear survival curves were experimentally obtained with D-values depending on discharge power. At $300 \mathrm{~W}$, a D-value of approximately 8 minutes was found, while at higher discharge powers ( 350 and $400 \mathrm{~W}$ ), the D-value decreased to approximately 3 minutes. Besides studying the influence of discharge power, Liu et al. (Liu et al., 2008) also examined the influence of other operating parameters on the inactivation of $E$. coli on poly(tetrafluoroethylene) (PTFE) films. These authors found, in accordance with Boscariol et al. (Boscariol et al., 2008), that the germicidal effect is higher at elevated discharge powers. They also experimentally confirmed that the inactivation effect increases with increasing plasma treatment time up to 50 seconds, after which it remains more or less stable. The authors also studied the difference between direct and remote plasma exposure by positioning the PTFE films at different distances varying from 0 to $80 \mathrm{~cm}$ from the centre of the induction coil. Samples placed in the region $0-30 \mathrm{~cm}$ from the centre of the coil are directly exposed to the plasma, while at larger distances, plasma treatment occurs in the afterglow mode. Figure 9 shows the germicidal effect as a function of distance from the 
induction coil and clearly shows that the oxygen plasma can effectively inactivate $E$. coli within a distance of $0-40 \mathrm{~cm}$. In the afterglow zone at $40 \mathrm{~cm}$ from the coil centre, the concentration of ions and electrons is nearly zero, while the concentration of oxygen radicals is still approximately $70 \%$ of the initial value. This afterglow treatment could be interesting to treat substrates prone to plasma-induced degradation.

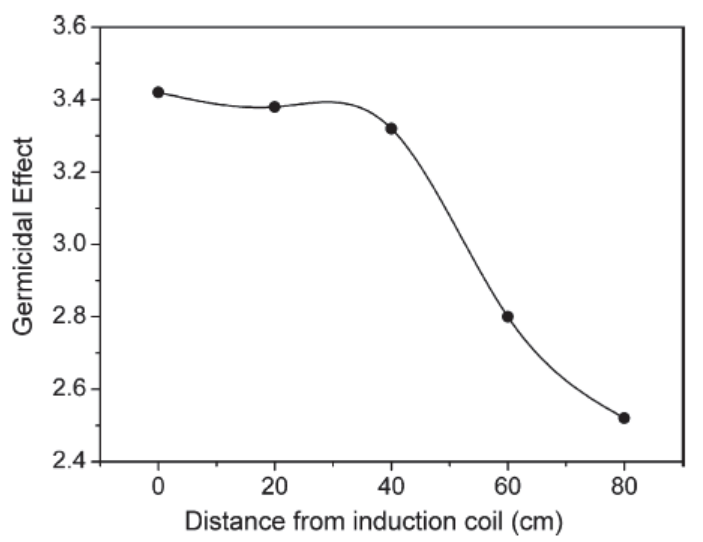

Fig. 9. Germicidal effect of an inductively coupled RF plasma sustained in oxygen at different distances from the induction coil [Reprinted with permission from (Liu et al., 2008)].

Besides pure oxygen plasmas, also low pressure $\mathrm{N}_{2} / \mathrm{O}_{2}$ plasmas have been widely investigated for the inactivation of bacteria (Moisan et al., 2002, Philip et al., 2002, Moreau et al., 2000, Rossi et al., 2006, Villeger et al., 2003, Villeger et al., 2005). Moreau et al. (Moreau et al., 2000) and Moisan et al. (Moisan et al., 2002) carried out detailed studies on the effects of a low pressure $\mathrm{N}_{2} / \mathrm{O}_{2}$ microwave plasma with biological samples placed in the afterglow of the discharge. Total inactivation of $B$. subtilis spores was achieved after 40 minutes of plasma exposure at $100 \mathrm{~W}$. In a following set of experiments, Philip et al. (Philip et al., 2002) studied the influence of oxygen percentage added to the nitrogen carrier gas on $B$. subtilis inactivation. Sterilization was achieved in less than 40 minutes with $0.7,1.5$ and $2 \%$ of added oxygen. In contrast, sterility was only reached after 80 minutes with $4 \%$ of added oxygen, while it was not even attained after 120 minutes with $7 \%$ of oxygen. The authors claim that the short sterilization times (which occur at oxygen percentages below $2 \%$ ) are due to the high UV intensity of the discharge, since the spores are only slightly eroded. Increasing the oxygen percentage in the mixture beyond this level increases the erosion rate of the spores, hence reducing more and more the dimensions of the spores. However, although the spores are heavily damaged, longer sterilization times are needed. The authors therefore state that the spores are mainly being inactivated by UV photons and not by erosion caused by reactive species. More recently, Rossi et al. (Rossi et al., 2006) claimed that the process determining the time to reach complete spore inactivation is etching rather than UV action, which is in contradiction with the paper written by Philip et al. (Philip et al., 2002). Rossi et al. (Rossi et al., 2006) employed an RF plasma for the inactivation of G. stearothermophilus spores and sterilization tests were performed in different $\mathrm{N}_{2} / \mathrm{O}_{2}$ mixtures ranging from a 
discharge in pure nitrogen to a pure oxygen one, which is a larger oxygen range than the one examined by Philip et al. (Philip et al., 2002). It was found that the best sterilization results were achieved in mixtures with high amounts of oxygen: complete sterilization was obtained in the $95 \% \mathrm{O}_{2}-5 \% \mathrm{~N}_{2}$ mixture within 5 minutes of plasma exposure and significant changes in the dimensions of the spores were observed for these discharges. In contrast, mixtures with low oxygen amounts, which produce high UV emission, resulted in low sterilization efficiencies and no variation in dimensions of the spores was found. The authors therefore claim that erosion caused by reactive species might after all be significant in the bacterial inactivation process. Recently, Kylian et al. (Kylian\&Rossi, 2009) demonstrated that the application of $\mathrm{Ar} / \mathrm{N}_{2} / \mathrm{O}_{2}$ plasmas offers the possibility to combine the advantageous properties of the binary mixtures, namely, the capability of an $\mathrm{N}_{2} / \mathrm{O}_{2}$ plasma to emit intense UV radiation needed for inactivation of bacterial spores together with high removal rates of biological substances from $\mathrm{Ar} / \mathrm{O}_{2}$ discharges.

\subsection{Atmospheric pressure plasmas}

Although the use of vacuum plasmas can be considered as a significant improvement over existing sterilization methods, there are still several drawbacks, including the need for batch processing, long processing times and high costs. As a result, in the past decades, interest has grown in applying atmospheric pressure plasmas for sterilization purposes and several methods have been developed that allowed researchers to easily generate non-thermal plasmas at high pressures, up to one atmosphere (Laroussi, 2005). In the following sections, the most commonly used atmospheric pressure plasmas sources for sterilization purposes will be briefly discussed together with some important results obtained for each of these discharge types.

\subsubsection{Dielectric barrier discharge (DBD)}

A widely used atmospheric pressure discharge for bacterial inactivation is the dielectric barrier discharge (DBD). In most cases, the plasma is created between closely spaced parallel plates, where one or two plates are covered by a dielectric layer (Kogelschatz et al., 1997, Kogelschatz, 2003). DBDs are generally driven by AC high voltages with frequencies in the $\mathrm{kHz}$ range and power consumptions between 10 and $100 \mathrm{~W}$ (Stoffels, 2007). Usually, a DBD operates in the filamentary mode: the breakdown starts at many points, followed by the development of independent current filaments, named microdischarges (Kogelschatz et al., 1997, Kogelschatz, 2003). However, it has been demonstrated that a homogeneous discharge can be obtained under special, quite restrictive conditions [83,84]. DBDs can be used for bacterial inactivation, but the narrow spacing between the electrodes makes it difficult to introduce thick samples. For these samples, remote DBD treatment can however be employed.

Laroussi et al. (Laroussi et al., 1999) demonstrated that a homogeneous helium/air DBD is effective for the inactivation of $E$. coli and observed that exposure times of 2 to 20 minutes can lead to complete inactivation. The authors also state that the treatment time necessary to obtain a complete kill depends on several parameters, such as plasma power, working gas, type of bacteria and type of medium. Using a similar pure air discharge, Kelly-Wintenberg et al. (Kelly-Wintenberg et al., 1999) reported on the inactivation of a broad spectrum of bacteria placed on a variety of surfaces. Experimental results have showed that at least a 5 $\log _{10}$ CFU reduction in bacteria can be achieved between 15 and 90 seconds of plasma 
exposure. An exception to these very short exposure times were experiments with solid culture media in which 5 minutes of plasma exposure was necessary to achieve the same reduction in CFU. To enable the exposure of large or complex three-dimensional samples, Roth et al. (Roth et al., 2000) developed a so-called remote exposure reactor, in which samples can be sterilized in the afterglow of an atmospheric pressure glow DBD. These authors found that besides direct exposure, also remote plasma treatment can achieve effective bacterial inactivation (Roth et al., 2000, Ben Gadri et al., 2000, Montie et al., 2000).

Besides DBDs in the homogeneous mode, also filamentary discharges have been employed for the sterilization of various bacteria (Kostov et al., 2010, Heise et al., 2004, Trompeter et al., 2002, Hahnel et al., 2010, Yasuda et al., 2008). Kostov et al. (Kostov et al., 2010) and Yasuda et al. (Yasuda et al., 2008) were able to achieve sterilization of E. coli with their filamentary air DBD, while Trompeter et al. (Trompeter et al., 2002) focussed on the inactivation of B. subtilis and Aspergillus Niger with DBDs sustained in different working gases. Heise et al. (Heise et al., 2004) observed that the spore reduction of B. subtilis depends on which working gas is used to sustain the DBD: the efficiency of the discharge is the lowest when air is employed and the highest with argon as discharge gas. More recently, Hähnel et al. (Hahnel et al., 2010) observed that air humidity in a dielectric barrier surface discharge has a significant influence on the bacterial inactivation rate: higher concentration of water vapour in the process gas leads to higher killing rates of micro-organisms.

To enable the internal sterilization of complicated medical instruments, such as breathing circuits, catheders and endoscopes, different authors have developed special DBD configurations (Eto et al., 2008, Pointu et al., 2008, Sato et al., 2008). Eto et al. (Eto et al., 2008) developed a so-called "linear DBD" with a diameter of $0.2-3 \mathrm{~mm}$ and a length of $40 \mathrm{~cm}$ and found that $10^{6} \mathrm{~B}$. stearothermophilus spores could be killed inside a medical plastic tube at room temperature after 12 minutes of air plasma exposure. Sato et al. (Sato et al., 2008) also report on a special type of $\mathrm{DBD}$ and demonstrated the efficacy of their DBD for tube sterilization. A photograph of their discharge in a long flexible narrow tube can be found in Figure 10 .

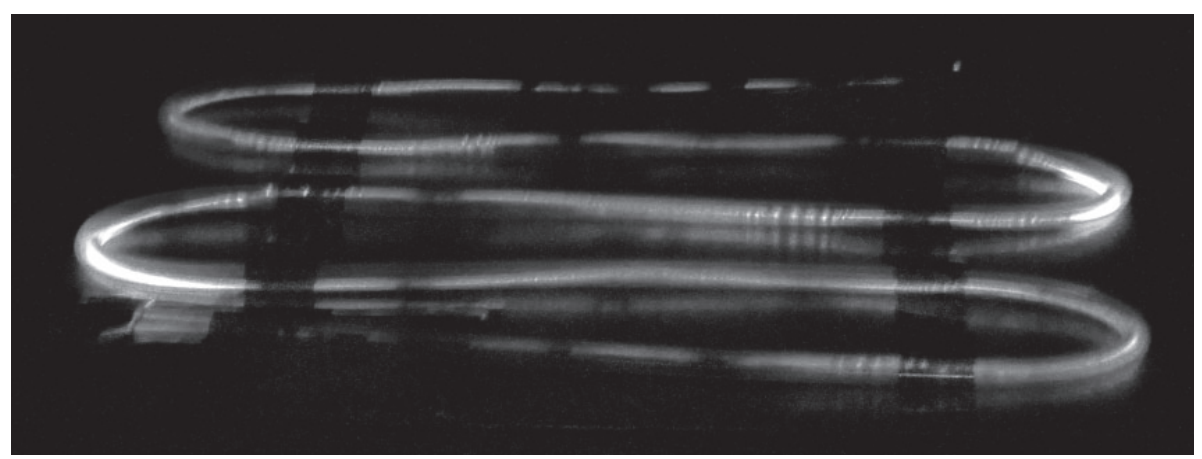

Fig. 10. Photograph of a DBD inside a tube for catheter sterilization [Reprinted with permission from (Sato et al., 2008)][91].

\subsubsection{Atmospheric pressure plasma jets}

Since the 1990s, an increasing interest in plasma jets for bacterial inactivation has been registered. Numerous plasma jets with different features have been developed and 
described in literature (Herrmann et al., 1999, Laroussi et al., 2006, Shimizu et al., 2008, Stoffels et al., 2006). These jets all differ in design, size, working gas, frequency of applied voltage,... but the principle is the same. The plasma is ignited inside a nozzle equipped with one or two electrodes and expands outside the nozzle via a gas flow. Atmospheric pressure plasmas jets are very practical due to their small size and light-weight plasma generation unit. They can be employed to treat small-sized objects, but can also be used for large-scale treatments by moving the jet over the selected area or by applying multiple nozzles next to each other. The following section will focus on the most important atmospheric pressure plasma jets employed for bacterial inactivation, however, it is important to mention that also other types of plasma jets have been developed for disinfection purposes (Shimizu et al., 2010, Chiang et al., 2010, Ikawa et al., 2010, Lee et al., 2005, Liu et al., 2010, Kim et al., 2009, Huang et al., 2007).

One type of plasma jet, which is actively employed for bacterial sterilization is the so-called "atmospheric pressure plasma jet (APPJ)". The design and operation of the APPJ have been already discussed in detail elsewhere (Jeong et al., 1998, Park et al., 2000, Schutze et al., 1998) and are only briefly summarized here for completeness. The APPJ consists of two coaxial electrodes between which a feed gas (mixtures of helium, oxygen and other gases) flows at high rate (50-100 litres per minute gas flow) and is schematically presented in Figure 11. By applying RF power $(50-100 \mathrm{~W})$ at $13.56 \mathrm{MHz}$ to the inner electrode, a spatially uniform discharge is ignited. The chemically active species, such as excited atoms, excited molecules and free radicals exit the nozzle at high velocity (jet length of $10 \mathrm{~mm}$ ) and impinge on the substrate being sterilized. Due to cooling by the high gas flow, the effluent temperature can be kept at moderate levels $\left(100^{\circ} \mathrm{C}\right)$. The ions and electrons quickly recombine outside the jet and are most likely not active in the bacterial inactivation process. Herrmann et al. (Herrmann et al., 1999) used the APPJ in a helium-oxygen mixture to inactivate spores of $B$. globigii and reported a reduction of seven orders of magnitude of the original concentration of $B$. globigii in approximately 30 seconds.

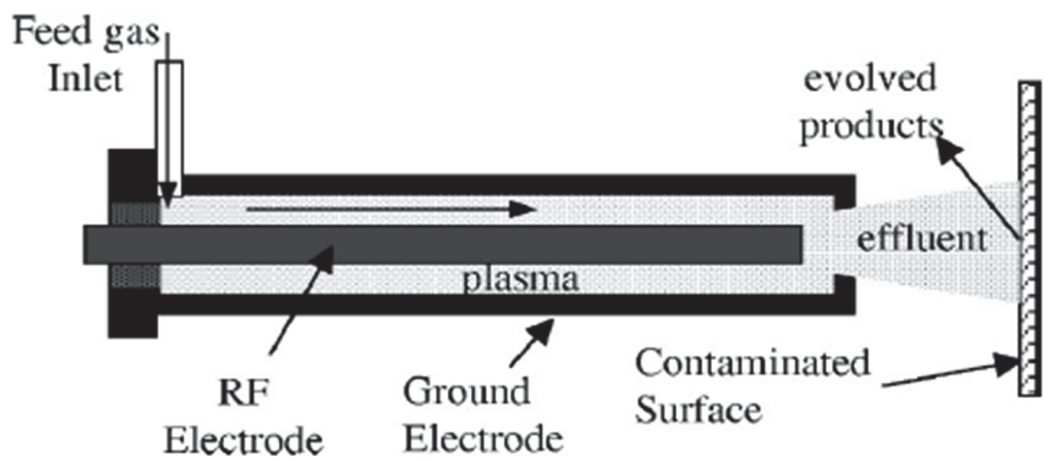

Fig. 11. Schematic representation of the atmospheric pressure plasma jet (APPJ) [Reprinted with permission from (Herrmann et al., 1999)].

A miniature jet was recently developed by Laroussi et al. (Laroussi et al., 2006, Lu\&Laroussi, 2006), who named their new plasma source "plasma pencil". The plasma pencil is basically a $2.5 \mathrm{~cm}$ diameter dielectric tube where two disk electrodes of about the same diameter as the tube are inserted. The electrodes are separated by a gap that can be varied from 0.5 to $1.0 \mathrm{~cm}$ 
and consist of a thin copper ring attached to the surface of a centrally perforated dielectric disk. To ignite the plasma, sub-microsecond square high voltage pulses at repetition rates in the $1-10 \mathrm{kHz}$ range are applied between the two electrodes and a gas mixture (such as helium/oxygen) is flown through the holes of the electrodes (flow rates between 1 and 10 litres per minute). When the discharge is ignited, a plasma plume with lengths up to $5 \mathrm{~cm}$ is launched through the hole of the outer electrode in the surrounding air. Figure 12 shows a photograph of the plume emitted by the plasma pencil. This plasma plume remains stable and maintains at room temperature for extended operating times. As a result, the plume can be touched by bare hands without any harm.

Preliminary experiments (Laroussi et al., 2006) have been recently carried out to test the effectiveness of the plasma pencil to inactive bacteria. In this study, E. coli has been treated with the plasma pencil in two different operating gases (helium and helium with $0.75 \%$ admixture of oxygen) for different treatment times (30 seconds and 120 seconds). Figure 13 shows the results of these tests: from these photographs, it can be concluded that the area of the inactivated region increases with increasing plasma exposure time and that the area of the inactivated region is much greater when oxygen was added to helium, especially for long treatment times.

Recently, the biomedical team at the Eindhoven University of Technology has introduced another concept of a miniature atmospheric plasma jet: the "plasma needle" (Stoffels et al., 2002, Stoffels et al., 2006). The portable plasma needle consists of a metal wire $(0.3 \mathrm{~mm}$ diameter) with a sharpened tip, confined in a Perspex tube (4 $\mathrm{mm}$ inner diameter). RF power at $13.05 \mathrm{MHz}$ ranging between $10 \mathrm{~mW}$ and several watts can be applied to the needle resulting in the generation of a micro-plasma (0.1-2 $\mathrm{mm}$ glow size). In the $10-300 \mathrm{~mW}$ regime, the gas temperature is close to body temperature, while above $1 \mathrm{~W}$, it can increase to $100^{\circ} \mathrm{C}$ and more (Stoffels, 2007). Because the voltage necessary to ignite the discharge is the lowest in helium, the plasma needle operates in helium-air mixtures. The Perspex tube is filled with helium at flow rates between 0.5 and 2.0 litres per minute, while the air content can be adjusted by pushing the needle in or out the Perspex tube: the more the needle protrudes from the tube, the more air can enter the plasma region (Sladek\&Stoffels, 2005). A photograph of the portable plasma needle and a close-up of the metal wire inside the Perspex tube can be seen in Figure 14.

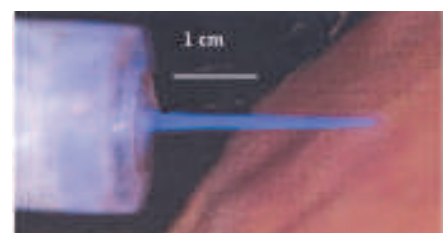

Fig. 12. Photograph of the plasma plume in contact with human skin [Reprinted with permission from (Lu\&Laroussi, 2006)].

Sladek et al. (Sladek\&Stoffels, 2005, Sladek et al., 2006) employed the plasma needle for the inactivation of $E$. coli films and observed that plasma treatment results in the formation of a bacteria-free void with a size up to $12 \mathrm{~mm}$. $10^{4}-10^{5}$ colony forming units could be destroyed after 10 seconds of plasma treatment at low power. The authors also state that prolongation of treatment time or usage of higher power does not significantly improve the destruction efficiency: short exposure at low plasma power is sufficient. 


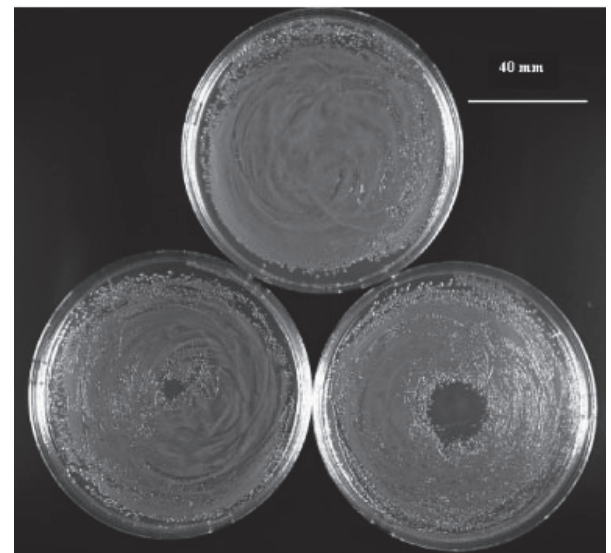

(a)

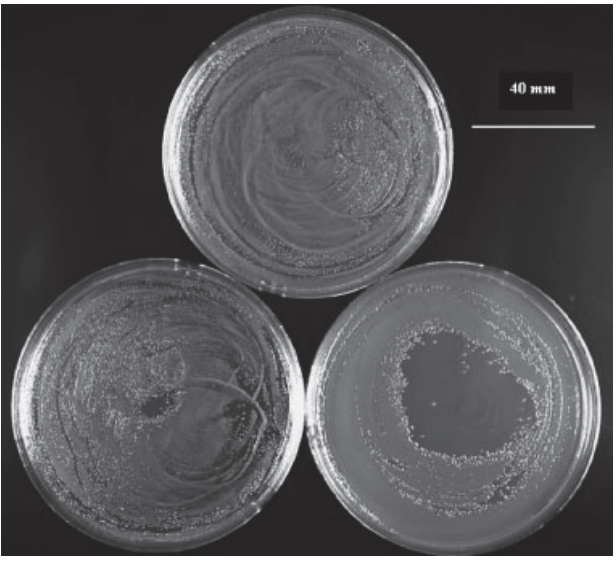

(b)

Fig. 13. Photographs of Petri dishes showing the effects of the plasma pencil on E. coli cells for the case of (a) pure helium; (b) helium $+0.75 \%$ oxygen. Top Petri dishes are untreated samples, bottom Petri dishes were treated for 30 seconds (left) and 120 seconds (right) [Reprinted with permission from (Laroussi et al., 2006)].

An atmospheric pressure plasma jet with a special design has been developed by Shimizu et al. (Shimizu et al., 2008) and applied for the inactivation of E. coli. This so-called "microwave plasma torch" consists of 6 stainless steel electrodes placed inside an aluminium cylinder. The centres of the electrodes are equally distributed at a distance of $6 \mathrm{~mm}$ from the inner surface of the cylinder. Microwave power of approximately $85 \mathrm{~W}$ at $2.45 \mathrm{GHz}$ is applied to the electrodes in flowing argon leading to the production of six plasma zones between each of the electrode tips and the inner surface of the cylinder, as shown in Figure 15. The authors observed that when an E. coli culture is placed for 2 minutes at $20 \mathrm{~mm}$ below the torch (where the gas temperature is sufficiently cool), the E. coli bacteria were almost completely killed within a $40 \mathrm{~mm}$ diameter.

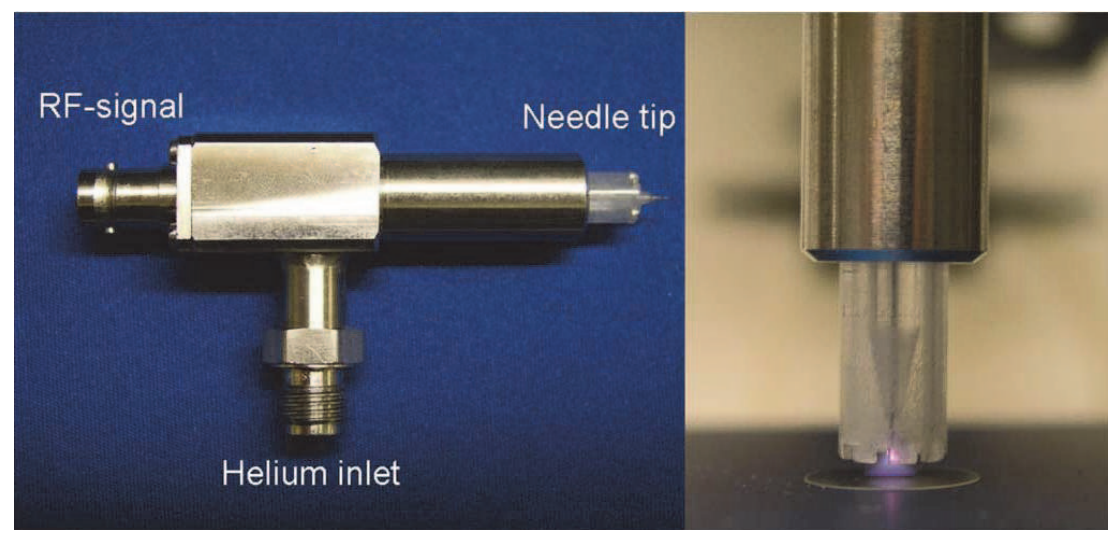

Fig. 14. Photograph of the portable plasma needle (left) and normal glow operation of the needle (right) [Reprinted with permission from (Sladek et al., 2006)]. 


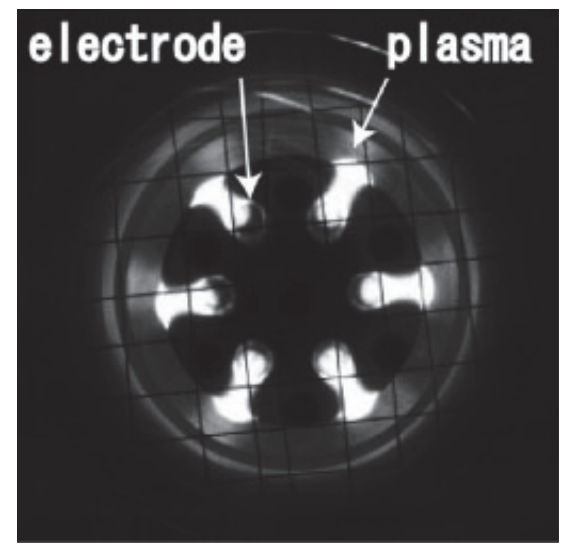

Fig. 15. Photograph of the microwave plasma torch with six plasma zones [Reprinted with permission from (Shimizu et al., 2008)].

\section{Plasma sterilization of animal and human living tissue}

\subsection{Plasma sterilization in dentistry}

Dental cavities, as the result of caries, are a common ailment and the improvement of current treatment methods is a major issue in dentistry (Sladek et al., 2004). Preparation of cavities prior to filling is done by removing necrotic, infected and non-remineralizable tissue by means of mechanical drilling or laser techniques (Banerjee et al., 2000). In both methods, heating takes place. Moreover, vibrations occur during mechanical drilling, which is usually quite painful for the patient since both heating as vibrations can stimulate the nerve (Banerjee et al., 2000). Moreover, these methods are often destructive: fractures can occur and an excess of healthy tissue must be removed to ensure that the cavity is free of bacteria (Sladek et al., 2004). A non-thermal atmospheric pressure plasma might offer a less destructive and less painful method to prepare dental cavities. These plasmas operate at room temperature and do not cause pain or bulk destruction of the tissue. Moreover, although the plasma is superficial, the active plasma species it produces can easily reach the inside of the cavity. Goree et al. (Goree et al., 2006b, Goree et al., 2006a) have employed the plasma needle to kill $S$. mutans, which is the main micro-organism causing dental caries. These authors found that the plasma needle can effectively kill these bacteria after 10 seconds of plasma treatment within a solid circle of $5 \mathrm{~mm}$ diameter, thereby demonstrating its site specific capabilities. As a result, the plasma needle can provide an attractive alternative for dental clinical treatment.

More recently, Jiang et al. (Jiang et al., 2009) have developed a hollow-electrode-based, 100ns-pulsed plasma dental probe that generates a tapered cylindrical plasma plume at room temperature in ambient atmosphere. This plasma plume causes minimal heating of biological materials and can be touched with bare hands without causing burning sensation or pain. After the developing phase, Jiang et al. (Jiang et al., 2009) used the plasma dental probe to disinfect root canals from extracted human teeth. For this purpose, two teeth were placed $5 \mathrm{~mm}$ below the plasma dental probe nozzle. One tooth was exposed to the helium/oxygen plasma for 5 minutes, while the other tooth, serving as control, was exposed to a similar helium/oxygen flow for the same amount of time, but with the plasma switched 
off. After treatment, the treated and control tooth were longitudinally and transversely split with a dental burr and subsequently examined with SEM, as shown in Figure 16. It can be clearly seen that in the case of the control tooth, biofilms cover the entire root canal surface. However, in the plasma-treated root canal, a distinct zone without biofilms (1 $\mathrm{mm}$ in depth) can be observed. However, the plasma failed to reach the lower zone. Nevertheless, the authors state that greater sterilization depth can be achieved by optimizing the width and the length of the plasma plume. Another solution to a better killing efficacy in root canals was provided by Lu et al. (Lu et al., 2009), who constructed a cold plasma jet device which is able to generate plasma inside the root canal. It was found that this device efficiently kills Enterococcus faecalis (one of the main types of bacteria causing failure of the root canal) within several minutes of plasma treatment. Although these preliminary results are very encouraging, a lot of basic issues still need more in-depth investigation before atmospheric pressure plasmas can be widely employed in dentistry.

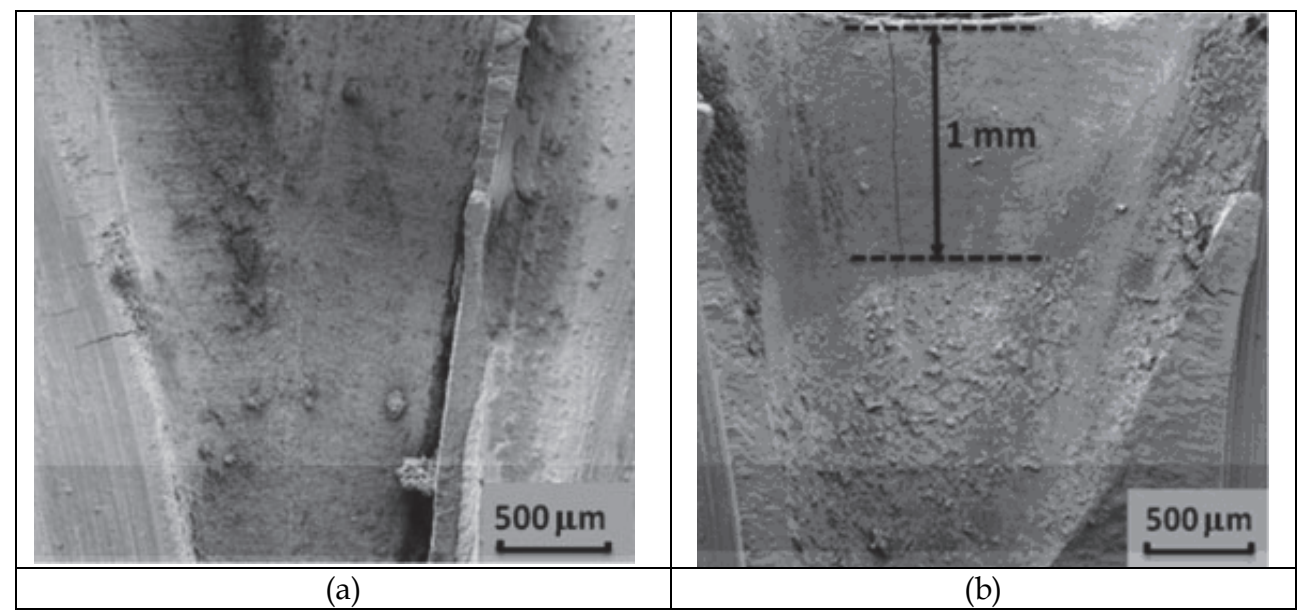

Fig. 16. (a) SEM image of the control split root canal and (b) SEM image of the split root canal after 5 minutes of plasma treatment [Reprinted with permission from (Jiang et al., 2009)].

\subsection{Plasma sterilization of human/animal skin}

Another interesting state-of-the-art application of non-thermal plasmas is the sterilization of human or animal skin, however, this is a recently developed research topic and has up to now only been examined by the research group of Alexander Fridman. In a hospital setting, sterilization of living animal or human tissue with minimal damage to this tissue is of great importance. Nowadays, chemical sterilization is commonly employed, however, this technique does not always offer a solution. For example, it cannot be used for the sterilization of open wounds, ulcers or burns due to the extent of damage they cause to punctured tissues. Transporting chemicals for sterilization can also become a major logistics problem for example in a military field hospital (Fridman, 2008). Non-thermal atmospheric pressure plasma sources can offer an interesting alternative since it is quite a potent disinfecting and sterilizing agent, as extensively discussed in the previous sections. As previously mentioned, it is crucial that the living tissue does not get damaged during 
plasma treatment, therefore, the discharge current should be limited below values acceptable for treatment of living tissue. Moreover, the discharge itself should be homogeneous enough to avoid local damage and discomfort (Fridman, 2008). The creation of special atmospheric pressure discharges effectively solving these problems is an important challenge and until now, only a few researchers succeeded in developing a nonthermal plasma suitable for living tissue sterilization. Fridman et al. (Fridman et al., 2006) especially developed a discharge for this purpose: the so-called floating-electrode DBD (FEDBD). Similar to the classical DBDs, the set-up consist of two electrodes: a dielectricprotected powered electrode and a second active electrode, which can be human or animal skin or an organ. This latter electrode is not grounded and remains at a floating potential. The discharge ignites when the powered electrode approaches the surface to be treated at a distance of less than $3 \mathrm{~mm}$, depending on the form, duration and polarity of the driving voltage. Figure 17 shows a photograph of the FE-DBD with human tissue as floating electrode.

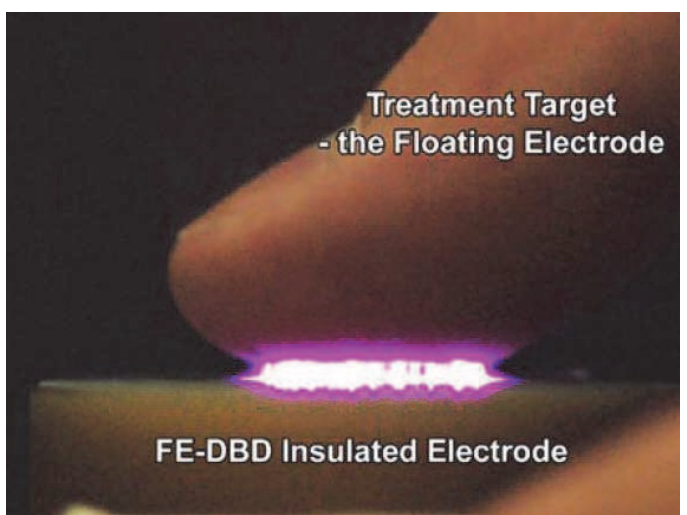

Fig. 17. FE-DBD for the sterilization of living tissue [Reprinted with permission from (Fridman et al., 2006)].

Recently, the FE-DBD has been further optimized to minimize the DBD non-uniformities and the related damaging effects. The best results were obtained when the FE-DBD was employed in the pulsed mode with pulse durations below 30-100 ns, resulting in sufficient uniformity and the possibility of non-damaging direct plasma treatment of living tissue (Ayan et al., 2009). Fridman et al. (Fridman et al., 2006) investigated human tissue sterilization by subjecting bacteria collected from cadaver skin containing Staphylococcus, Streptococcus and yeast to their FE-DBD. The authors observed that sterilization generally occurred within 4 seconds while in some cases a 6 second plasma treatment was found to be necessary. To examine whether living tissue remains intact after FE-DBD treatment, cadaver tissue was plasma-treated for up to 5 minutes showing no visible or microscopic changes in the tissue (Fridman et al., 2006). Subsequently, an animal model (SKH1 hairless mouse) was subjected to the plasma with varying doses to determine the damaging dose. First, an animal was treated at what was deemed to be a damaging dose based on trials with cadaver skin tissue (Fridman, 2008). Once the dose where the damage was visible was determined, a new animal was treated at a lower dose. If no damage is observed at that dose, two more animals were treated and if no damage occurred in all three cases, the dose was deemed 
"maximum acceptable dose". Once this maximum dose was determined, three animals were treated at that dose and left alive under close observation for 2 weeks. These tests have shown that the animals remain fine after a reasonably high plasma dose. Following the investigation in mice, a similar investigation was carried out on pigs, achieving the same results. Based on these findings, the authors concluded that atmospheric pressure nonthermal plasmas can thus be an efficient tool for the sterilization of living tissue. This conclusion opens interesting perspectives for non-thermal plasma applications in medicine, including pre-surgical patient treatment, sterilization of wounds and burns as well as treatment of internal organs.

\section{Conclusions}

During the last decades, the plasma community has witnessed a burst of research activity on the germicidal properties of both low pressure as well as atmospheric pressure non-thermal plasmas. While vacuum-based plasma sterilization is an already well-established technology, the use of atmospheric pressure cold plasmas for the inactivation of bacteria is a relatively recent event. As a result, there are still a lot of issues in atmospheric pressure plasma sterilization that need more in-depth investigations. For example, there is still no complete understanding of the biological pathways that cold atmospheric pressure plasmas induce in cells and tissues during treatment. Although preliminary results are very promising, a lot of work requiring collaborative efforts between plasma scientists, microbiologists and biochemists remains to be done before plasma can establish itself as a technique being routinely and effectively used for sterilization purposes. Despite all these challenges, non-thermal plasmas have undoubtedly great potential as a novel method for low temperature sterilization. Due to the growing amount of information and expertise on this subject, it seems to be most likely that real life applications of non-thermal plasmas for sterilization purposes will become a reality in the near future.

\section{References}

Ashman, L. E. \& Menashi, W. P. 1972. Treatment of surfaces with low pressure plasmas.

Ayan, H., Fridman, G., Staack, D., Gutsol, A. F., Vasilets, V. N., Fridman, A. A. \& Friedman, G. 2009. Heating Effect of Dielectric Barrier Discharges for Direct Medical Treatment. IEEE Transactions on Plasma Science, 37, 113-120.

Banerjee, A., Watson, T. F. \& Kidd, E. A. M. 2000. Dentine caries excavation: a review of current clinical techniques. British Dental Journal, 188, 476-482.

Ben Gadri, R., Roth, J. R., Montie, T. C., Kelly-Wintenberg, K., Tsai, P. P. Y., Helfritch, D. J., Feldman, P., Sherman, D. M., Karakaya, F. \& Chen, Z. Y. 2000. Sterilization and plasma processing of room temperature surfaces with a one atmosphere uniform glow discharge plasma (OAUGDP). Surface E Coatings Technology, 131, 528-542.

Birmingham, J. G. 2004. Mechanisms of bacterial spore deactivation using ambient pressure nonthermal discharges. IEEE Transactions on Plasma Science, 32, 15261531.

Bithell, R. M. 1982. Package and sterilizing process for same.

Bogaerts, A., Neyts, E., Gijbels, R. \& van der Mullen, J. 2002. Gas discharge plasmas and their applications. Spectrochimica Acta Part B-Atomic Spectroscopy, 57, 609-658. 
Bol'shakov, A. A., Cruden, B. A., Mogul, R., Rao, M. V. V. S., Sharma, S. P., Khare, B. N. \& Meyyappan, M. 2004. Radio-frequency oxygen plasma as a sterilization source. Aiaa Journal, 42, 823-832.

Borcia, G., Anderson, C. A. \& Brown, N. M. D. 2006. Surface treatment of natural and synthetic textiles using a dielectric barrier discharge. Surface $\mathcal{E}$ Coatings Technology, 201, 3074-3081.

Boscariol, M. R., Moreira, A. J., Mansano, R. D., Kikuchi, I. S. \& Pinto, T. J. A. 2008. Sterilization by pure oxygen plasma and by oxygen-hydrogen peroxide plasma: An efficacy study. International Journal of Pharmaceutics, 353, 170-175.

Boudam, M. K., Moisan, M., Saoudi, B., Popovici, C., Gherardi, N. \& Massines, F. 2006. Bacterial spore inactivation by atmospheric-pressure plasmas in the presence or absence of UV photons as obtained with the same gas mixture. Journal of Physics D-Applied Physics, 39, 3494-3507.

Bruce, R. L., Lin, T., Phaneuf, R. J., Oehrlein, G. S., Bell, W., Long, B. \& Willson, C. G. 2010. Molecular structure effects on dry etching behavior of Si-containing resists in oxygen plasma. Journal of Vacuum Science \& Technology B, 28, 751-757.

Cariou-Travers, S. \& Darbord, J. C. 2001. Validation of plasma sterilization - The case of Sterrad. Vide-Science Technique et Applications, 56, 34-46.

Chau, T. T., Kao, K. C., Blank, G. \& Madrid, F. 1996. Microwave plasmas for lowtemperature dry sterilization. Biomaterials, 17, 1273-1277.

Chiang, M. H., Wu, J. Y., Li, Y. H., Wu, J. S., Chen, S. H. \& Chang, C. L. 2010. Inactivation of E. coli and B. subtilis by a parallel-plate dielectric barrier discharge jet. Surface $\mathcal{E}$ Coatings Technology, 204, 3729-3737.

Choi, J. H., Han, I., Baik, H. K., Lee, M. H., Han, D. W., Park, J. C., Lee, I. S., Song, K. M. \& Lim, Y. S. 2006. Analysis of sterilization effect by pulsed dielectric barrier discharge. Journal of Electrostatics, 64, 17-22.

Cvelbar, U., Vujosevic, D., Vratnica, Z. \& Mozetic, M. 2006. The influence of substrate material on bacteria sterilization in an oxygen plasma glow discharge. Journal of Physics D-Applied Physics, 39, 3487-3493.

Daeschlein, G., von Woedtke, T., Kindel, E., Brandenburg, R., Weltmann, K. D. \& Junger, M. 2010. Antibacterial Activity of an Atmospheric Pressure Plasma Jet Against Relevant Wound Pathogens in vitro on a Simulated Wound Environment. Plasma Processes and Polymers, 7, 224-230.

De Geyter, N., Morent, R., Gengembre, L., Leys, C., Payen, E., Van Vlierberghe, S. \& Schacht, E. 2008. Increasing the Hydrophobicity of a PP Film Using a Helium/CF 4 DBD Treatment at Atmospheric Pressure. Plasma Chemistry and Plasma Processing, 28, 289-298.

De Geyter, N., Morent, R., Van Vlierberghe, S., Dubruel, P., Leys, C., Gengembre, L., Schacht, E. \& Payen, E. 2009. Deposition of polymethyl methacrylate on polypropylene substrates using an atmospheric pressure dielectric barrier discharge. Progress in Organic Coatings, 64, 230-237.

Denes, F. S. \& Manolache, S. 2004. Macromolecular plasma-chemistry: an emerging field of polymer science. Progress in Polymer Science, 29, 815-885. 
Eto, H., Ono, Y., Ogino, A. \& Nagatsu, M. 2008. Low-temperature internal sterilization of medical plastic tubes using a linear dielectric barrier discharge. Plasma Processes and Polymers, 5, 269-274.

Fraser, S. J., Gillette, R. B. \& Olson, R. L. 1976. Sterilizing process and apparatus utilizing gas plasma.

Fridman, A. 2008. Plasma Biology and Plasma Medicine. Plasma Chemistry. New York: Cambridge University Press.

Fridman, G., Brooks, A. D., Balasubramanian, M., Fridman, A., Gutsol, A., Vasilets, V. N., Ayan, H. \& Friedman, G. 2007. Comparison of direct and indirect effects of nonthermal atmospheric-pressure plasma on bacteria. Plasma Processes and Polymers, 4, 370-375.

Fridman, G., Friedman, G., Gutsol, A., Shekhter, A. B., Vasilets, V. N. \& Fridman, A. 2008. Applied plasma medicine. Plasma Processes and Polymers, 5, 503-533.

Fridman, G., Peddinghaus, M., Ayan, H., Fridman, A., Balasubramanian, M., Gutsol, A., Brooks, A. \& Friedman, G. 2006. Blood coagulation and living tissue sterilization by floating-electrode dielectric barrier discharge in air. Plasma Chemistry and Plasma Processing, 26, 425-442.

Gopal, N. G. S. 1978. Radiation Sterilization of Pharmaceuticals and Polymers. Radiation Physics and Chemistry, 12, 35-50.

Goree, J., Liu, B. \& Drake, D. 2006a. Gas flow dependence for plasma-needle disinfection of S-mutans bacteria. Journal of Physics D-Applied Physics, 39, 3479-3486.

Goree, J., Liu, B., Drake, D. \& Stoffels, E. 2006b. Killing of S-mutans bacteria using a plasma needle at atmospheric pressure. IEEE Transactions on Plasma Science, 34, 1317-1324.

Gut Boucher, R. M. 1980. Seeded gas plasma sterilization method.

Hahnel, M., von Woedtke, T. \& Weltmann, K. D. 2010. Influence of the Air Humidity on the Reduction of Bacillus Spores in a Defined Environment at Atmospheric Pressure Using a Dielectric Barrier Surface Discharge. Plasma Processes and Polymers, 7, 244-249.

Heise, M., Neff, W., Franken, O., Muranyi, P. \& Wunderlich, J. 2004. Sterilization of polymer foils with dielectric barrier discharges at atmospheric pressure. Plasmas and Polymers, 9, 23-33.

Henn, G. G., Birkinshaw, C., Buggy, M. \& Jones, E. 1996. A comparison of the effects of gamma-irradiation and ethylene oxide sterilization on the properties of compression moulded poly-d,l-lactide. Journal of Materials Science-Materials in Medicine, 7, 591-595.

Herrmann, H. W., Henins, I., Park, J. \& Selwyn, G. S. 1999. Decontamination of chemical and biological warfare, (CBW) agents using an atmospheric pressure plasma jet (APPJ). Physics of Plasmas, 6, 2284-2289.

Huang, C., Yu, Q. S., Hsieh, F. H. \& Duan, Y. X. 2007. Bacterial deactivation using a low temperature argon atmospheric plasma brush with oxygen addition. Plasma Processes and Polymers, 4, 77-87. 
Hury, S., Vidal, D. R., Desor, F., Pelletier, J. \& Lagarde, T. 1998. A parametric study of the destruction efficiency of Bacillus spores in low pressure oxygen-based plasmas. Letters in Applied Microbiology, 26, 417-421.

Ikawa, S., Kitano, K. \& Hamaguchi, S. 2010. Effects of $\mathrm{pH}$ on Bacterial Inactivation in Aqueous Solutions due to Low-Temperature Atmospheric Pressure Plasma Application. Plasma Processes and Polymers, 7, 33-42.

Ishigaki, I. \& Yoshii, F. 1992. Radiation Effects on Polymer Materials in Radiation Sterilization of Medical Supplies. Radiation Physics and Chemistry, 39, 527-533.

Jacobs, P. T. \& Lin, S. M. 1987. Hydrogen peroxide plasma sterilization system.

Jeong, J. Y., Babayan, S. E., Tu, V. J., Park, J., Henins, I., Hicks, R. F. \& Selwyn, G. S. 1998. Etching materials with an atmospheric-pressure plasma jet. Plasma Sources Science E Technology, 7, 282-285.

Jiang, C. Q., Chen, M. T., Gorur, A., Schaudinn, C., Jaramillo, D. E., Costerton, J. W., Sedghizadeh, P. P., Vernier, P. T. \& Gundersen, M. A. 2009. Nanosecond Pulsed Plasma Dental Probe. Plasma Processes and Polymers, 6, 479-483.

Kalghatgi, S., Friedman, G., Fridman, A. \& Clyne, A. M. 2010. Endothelial Cell Proliferation is Enhanced by Low Dose Non-Thermal Plasma Through Fibroblast Growth Factor-2 Release. Annals of Biomedical Engineering, 38, 748-757.

Kalghatgi, S. U., Fridman, G., Cooper, M., Nagaraj, G., Peddinghaus, M., Balasubramanian, M., Vasilets, V. N., Gutsol, A. F., Fridman, A. \& Friedman, G. 2007. Mechanism of blood coagulation by nonthermal atmospheric pressure dielectric barrier discharge plasma. IEEE Transactions on Plasma Science, 35, 15591566.

Kelly-Wintenberg, K., Hodge, A., Montie, T. C., Deleanu, L., Sherman, D., Roth, J. R., Tsai, P. \& Wadsworth, L. 1999. Use of a one atmosphere uniform glow discharge plasma to kill a broad spectrum of microorganisms. Journal of Vacuum Science $\mathcal{E}$ Technology A-Vacuum Surfaces and Films, 17, 1539-1544.

Kelly-Wintenberg, K., Montie, T. C., Brickman, C., Roth, J. R., Carr, A. K., Sorge, K., Wadsworth, L. C. \& Tsai, P. P. Y. 1998. Room temperature sterilization of surfaces and fabrics with a One Atmosphere Uniform Glow Discharge Plasma. Journal of Industrial Microbiology \& Biotechnology, 20, 69-74.

Kim, S. J., Chung, T. H., Bae, S. H. \& Leem, S. H. 2009. Characterization of Atmospheric Pressure Microplasma Jet Source and its Application to Bacterial Inactivation. Plasma Processes and Polymers, 6, 676-685.

Kogelschatz, U. 2003. Dielectric-barrier discharges: Their history, discharge physics, and industrial applications. Plasma Chemistry and Plasma Processing, 23, 1-46.

Kogelschatz, U., Eliasson, B. \& Egli, W. 1997. Dielectric-barrier discharges. Principle and applications. Journal de Physique IV, 7, 47-66.

Kong, M. G., Kroesen, G., Morfill, G., Nosenko, T., Shimizu, T., van Dijk, J. \& Zimmermann, J. L. 2009. Plasma medicine: an introductory review. New Journal of Physics, 11.

Kostov, K. G., Rocha, V., Koga-Ito, C. Y., Matos, B. M., Algatti, M. A., Honda, R. Y., Kayama, M. E. \& Mota, R. P. 2010. Bacterial sterilization by a dielectric barrier discharge (DBD) in air. Surface $\mathcal{E}$ Coatings Technology, 204, 2954-2959. 
Kuzmichev, A. I., Soloshenko, I. A., Tsiolko, V. V., Kryzhanovsky, V. I., Bazhenov, V. Y., Mikhno, I. L. \& Khomich, V. A. Year. Feature of sterilization by different type of atmopsheric pressure discharges. In: 7th International Symposium on High Pressure Low Temperature Plasma Chemistry - Hakone VII, 20012000 Greifswald (Germany). 402-406.

Kylian, O. \& Rossi, F. 2009. Sterilization and decontamination of medical instruments by low-pressure plasma discharges: application of Ar/O-2/N-2 ternary mixture. Journal of Physics D-Applied Physics, 42.

Langmuir, I. 1928. Oscillations in ionized gases. Proceedings of the National Academy of Sciences of the United States of America, 14, 627-637.

Laroussi, M. 1996. Sterilization of contaminated matter with an atmospheric pressure plasma. IEEE Transactions on Plasma Science, 24, 1188-1191.

Laroussi, M. 2002. Nonthermal decontamination of biological media by atmosphericpressure plasmas: Review, analysis, and prospects. IEEE Transactions on Plasma Science, 30, 1409-1415.

Laroussi, M. 2005. Low temperature plasma-based sterilization: Overview and state-ofthe-art. Plasma Processes and Polymers, 2, 391-400.

Laroussi, M. 2009. Low-Temperature Plasmas for Medicine? IEEE Transactions on Plasma Science, 37, 714-725.

Laroussi, M., Alexeff, I. \& Kang, W. L. 2000. Biological decontamination by nonthermal plasmas. IEEE Transactions on Plasma Science, 28, 184-188.

Laroussi, M. \& Leipold, F. 2004. Evaluation of the roles of reactive species, heat, and UV radiation in the inactivation of bacterial cells by air plasmas at atmospheric pressure. International Journal of Mass Spectrometry, 233, 81-86.

Laroussi, M., Sayler, G. S., Glascock, B. B., McCurdy, B., Pearce, M. E., Bright, N. G. \& Malott, C. M. 1999. Images of biological samples undergoing sterilization by a glow discharge at atmospheric pressure. IEEE Transactions on Plasma Science, 27, 34-35.

Laroussi, M., Tendero, C., Lu, X., Alla, S. \& Hynes, W. L. 2006. Inactivation of bacteria by the plasma pencil. Plasma Processes and Polymers, 3, 470-473.

Lee, K. Y., Park, B. J., Lee, D. H., Lee, I. S., Hyun, S. O., Chung, K. H. \& Park, J. C. 2005. Sterilization of Escherichia coli and MRSA using microwave-induced argon plasma at atmospheric pressure. Surface \& Coatings Technology, 193, 35-38.

Liu, F. X., Sun, P., Bai, N., Tian, Y., Zhou, H. X., Wei, S. C., Zhou, Y. H., Zhang, J., Zhu, W. D., Becker, K. \& Fang, J. 2010. Inactivation of Bacteria in an Aqueous Environment by a Direct-Current, Cold-Atmospheric-Pressure Air Plasma Microjet. Plasma Processes and Polymers, 7, 231-236.

Liu, H., Chen, J., Yang, L. \& Zhou, Y. 2008. Long-distance oxygen plasma sterilization: Effects and mechanisms. Applied Surface Science, 254, 1815-1821.

Liu, H. X. \& Chen, J. R. 2008. Analysis of surface sterilization and properties of medical poly (tetrafluoroethylene) in remote argon plasma. IEEE Transactions on Plasma Science, 36, 230-236.

Lu, X. \& Laroussi, M. 2006. Dynamics of an atmospheric pressure plasma plume generated by submicrosecond voltage pulses. Journal of Applied Physics, 100. 
Lu, X. P., Cao, Y. G., Yang, P., Xiong, Q., Xiong, Z. L., Xian, Y. B. \& Pan, Y. 2009. An RC Plasma Device for Sterilization of Root Canal of Teeth. IEEE Transactions on Plasma Science, 37, 668-673.

Maruyama, T., Narukage, T., Onuki, R. \& Fujiwara, N. 2010. High-aspect-ratio deep Si etching in SF6/O-2 plasma. I. Characteristics of radical reactions with highaspect-ratio patterns. Journal of Vacuum Science \& Technology B, 28, 854-861.

Mendis, D. A., Rosenberg, M. \& Azam, F. 2000. A note on the possible electrostatic disruption of bacteria. IEEE Transactions on Plasma Science, 28, 1304-1306.

Moisan, M., Barbeau, J., Crevier, M. C., Pelletier, J., Philip, N. \& Saoudi, B. 2002. Plasma sterilization. Methods mechanisms. Pure and Applied Chemistry, 74, 349-358.

Moisan, M., Barbeau, J., Moreau, S., Pelletier, J., Tabrizian, M. \& Yahia, L. H. 2001. Lowtemperature sterilization using gas plasmas: a review of the experiments and an analysis of the inactivation mechanisms. International Journal of Pharmaceutics, 226, $1-21$.

Montie, T. C., Kelly-Wintenberg, K. \& Roth, J. R. 2000. An overview of research using the one atmosphere uniform glow discharge plasma (OAUGDP) for sterilization of surfaces and materials. IEEE Transactions on Plasma Science, 28, 41-50.

Moreau, S., Moisan, M., Tabrizian, M., Barbeau, J., Pelletier, J., Ricard, A. \& Yahia, L. 2000. Using the flowing afterglow of a plasma to inactivate Bacillus subtilis spores: Influence of the operating conditions. Journal of Applied Physics, 88, 1166-1174.

Morent, R., De Geyter, N., Jacobs, T., Van Vlierberghe, S., Dubruel, P., Leys, C. \& Schacht, E. 2009a. Plasma-Polymerization of HMDSO Using an Atmospheric Pressure Dielectric Barrier Discharge. Plasma Processes and Polymers, 6, S537-S542.

Morent, R., De Geyter, N., Van Vlierberghe, S., Dubruel, P., Leys, C. \& Schacht, E. 2009b. Organic-inorganic behaviour of HMDSO films plasma-polymerized at atmospheric pressure. Surface $\mathcal{E}$ Coatings Technology, 203, 1366-1372.

Nagatsu, M., Terashita, F. \& Koide, Y. 2003. Low-temperature sterilization with surfacewave-excited oxygen plasma. Japanese Journal of Applied Physics Part 2-Letters $\mathcal{E}$ Express Letters, 42, L856-L859.

Nelson, C. L. \& Berger, T. J. 1989. Inactivation of Microorganisms by Oxygen Gas Plasma. Current Microbiology, 18, 275-276.

Nie, Q. Y., Cao, Z., Ren, C. S., Wang, D. Z. \& Kong, M. G. 2009. A two-dimensional cold atmospheric plasma jet array for uniform treatment of large-area surfaces for plasma medicine. New Journal of Physics, 11.

Park, B. J., Lee, D. H., Park, J. C., Lee, I. S., Lee, K. Y., Hyun, S. O., Chun, M. S. \& Chung, K. H. 2003. Sterilization using a microwave-induced argon plasma system at atmospheric pressure. Physics of Plasmas, 10, 4539-4544.

Park, J., Henins, I., Herrmann, H. W., Selwyn, G. S., Jeong, J. Y., Hicks, R. F., Shim, D. \& Chang, C. S. 2000. An atmospheric pressure plasma source. Applied Physics Letters, 76, 288-290.

Philip, N., Saoudi, B., Crevier, M. C., Moisan, M., Barbeau, J. \& Pelletier, J. 2002. The respective roles of $\mathrm{UV}$ photons and oxygen atoms in plasma sterilization at reduced gas pressure: The case of N-2-O-2 mixtures. IEEE Transactions on Plasma Science, 30, 1429-1436. 
Pointu, A. M., Ricard, A., Odic, E. \& Ganciu, M. 2008. Nitrogen atmospheric pressure post discharges for surface biological decontamination inside small diameter tubes. Plasma Processes and Polymers, 5, 559-568.

Purevdorj, D., Igura, N., Ariyada, O. \& Hayakawa, I. 2003. Effect of feed gas composition of gas discharge plasmas on Bacillus pumilus spore mortality. Letters in Applied Microbiology, 37, 31-34.

Ratner, B. D., Chilkoti, A. \& Lopez, G. P. 1990. Plasma Deposition and Treatment for Biomaterial Applications. In: D'AGOSTINO, R. (ed.) Plasma Deposition, Treatment, and Etching of Polymers. San Diego: Academic Press, Inc.

Richardson, J. P., Dyer, F. F., Dobbs, F. C., Alexeff, I. \& Laroussi, M. Year. On the use of the resistive barrier discharge to kill bacteria: Recent results. In: 27th IEEE International Conference on Plasma Science - ICOPS2000, 20002000 New Orleans (USA). 109-109.

Rossi, F., Kylian, O. \& Hasiwa, M. 2006. Decontamination of surfaces by low pressure plasma discharges. Plasma Processes and Polymers, 3, 431-442.

Rossi, F., Kylian, O., Rauscher, H., Gilliland, D. \& Sirghi, L. 2008. Use of a low-pressure plasma discharge for the decontamination and sterilization of medical devices. Pure and Applied Chemistry, 80, 1939-1951.

Roth, J. R., Sherman, D. M., Ben Gadri, R., Karakaya, F., Chen, Z. Y., Montie, T. C., KellyWintenberg, K. \& Tsai, P. P. Y. 2000. A remote exposure reactor (RER) for plasma processing and sterilization by plasma active species at one atmosphere. IEEE Transactions on Plasma Science, 28, 56-63.

Rutala, W. A., Gergen, M. F. \& Weber, D. J. 1998. Comparative evaluation of the sporicidal activity of new low-temperature sterilization technologies: Ethylene oxide, 2 plasma sterilization systems, and liquid peracetic acid. American Journal of Infection Control, 26, 393-398.

Sato, T., Furuya, O., Ikeda, K. \& Nakatani, T. 2008. Generation and transportation mechanisms of chemically active species by dielectric barrier discharge in a tube for catheter sterilization. Plasma Processes and Polymers, 5, 606-614.

Schutze, A., Jeong, J. Y., Babayan, S. E., Park, J., Selwyn, G. S. \& Hicks, R. F. 1998. The atmospheric-pressure plasma jet: A review and comparison to other plasma sources. IEEE Transactions on Plasma Science, 26, 1685-1694.

Shimizu, T., Nosenko, T., Morfill, G. E., Sato, T., Schmidt, H. U. \& Urayama, T. 2010. Characterization of Low-Temperature Microwave Plasma Treatment With and Without UV Light for Disinfection. Plasma Processes and Polymers, 7, 288-293.

Shimizu, T., Steffes, B., Pompl, R., Jamitzky, F., Bunk, W., Ramrath, K., Georgi, M., Stolz, W., Schmidt, H. U., Urayama, T., Fujii, S. \& Morfill, G. E. 2008. Characterization of microwave plasma torch for decontamination. Plasma Processes and Polymers, 5, 577-582.

Singh, M. K., Ogino, A. \& Nagatsu, M. 2009. Inactivation factors of spore-forming bacteria using low-pressure microwave plasmas in an $\mathrm{N}-2$ and $\mathrm{O}-2$ gas mixture. New Journal of Physics, 11. 
Sladek, R. E. J., Baede, T. A. \& Stoffels, E. 2006. Plasma-needle treatment of substrates with respect to wettability and growth of Escherichia coli and Streptococcus mutans. IEEE Transactions on Plasma Science, 34, 1325-1330.

Sladek, R. E. J. \& Stoffels, E. 2005. Deactivation of Escherichia coli by the plasma needle. Journal of Physics D-Applied Physics, 38, 1716-1721.

Sladek, R. E. J., Stoffels, E., Walraven, R., Tielbeek, P. J. A. \& Koolhoven, R. A. 2004. Plasma treatment of dental cavities: A feasibility study. IEEE Transactions on Plasma Science, 32, 1540-1543.

Stoffels, E. 2007. "Tissue processing" with atmospheric plasmas. Contributions to Plasma Physics, 47, 40-48.

Stoffels, E., Flikweert, A. J., Stoffels, W. W. \& Kroesen, G. M. W. 2002. Plasma needle: a non-destructive atmospheric plasma source for fine surface treatment of (bio)materials. Plasma Sources Science E Technology, 11, 383-388.

Stoffels, E., Kieft, I. E. \& Sladek, R. E. J. 2003. Superficial treatment of mammalian cells using plasma needle. Journal of Physics D-Applied Physics, 36, 2908-2913.

Stoffels, E., Kieft, I. E., Sladek, R. E. J., van den Bedem, L. J. M., van der Laan, E. P. \& Steinbuch, M. 2006. Plasma needle for in vivo medical treatment: recent developments and perspectives. Plasma Sources Science \& Technology, 15, S169S180.

Stoffels, E., Sakiyama, Y. \& Graves, D. B. 2008. Cold atmospheric plasma: Charged species and their interactions with cells and tissues. IEEE Transactions on Plasma Science, 36, 1441-1457.

Trompeter, F. J., Neff, W. J., Franken, O., Heise, M., Neiger, M., Liu, S. H., Pietsch, G. J. \& Saveljew, A. B. 2002. Reduction of Bacillus Subtilis and Aspergillus Niger spores using nonthermal atmospheric gas discharges. IEEE Transactions on Plasma Science, 30, 1416-1423.

Vandamme, M., Robert, E., Pesnel, S., Barbosa, E., Dozias, S., Sobilo, J., Lerondel, S., Le Pape, A. \& Pouvesle, J. M. 2010. Antitumor Effect of Plasma Treatment on U87 Glioma Xenografts: Preliminary Results. Plasma Processes and Polymers, 7, 264-273.

Vassal, S., Favennec, L., Ballet, J. J. \& Brasseur, P. 1998. Hydrogen peroxide gas plasma sterilization is effective against Cryptosporidium parvum oocysts. American Journal of Infection Control, 26, 136-138.

Vicoveanu, D., Popescu, S., Ohtsu, Y. \& Fujita, H. 2008. Competing inactivation agents for bacterial spares in radio-frequency oxygen plasmas. Plasma Processes and Polymers, 5, 350-358.

Villeger, S., Cousty, S., Ricard, A. \& Sixou, M. 2003. Sterilization of E-coli bacterium in a flowing N-2-O-2 post-discharge reactor. Journal of Physics D-Applied Physics, 36, L60-L62.

Villeger, S., Sarrette, J. P. \& Ricard, A. 2005. Synergy between N and O atom action and substrate surface temperature in a sterilization process using a flowing $\mathrm{N}-2-\mathrm{O}-2$ microwave post discharge. Plasma Processes and Polymers, 2, 709-714.

Yamamoto, M., Nishioka, M. \& Sadakata, M. Year. Sterilization using a corona discharge with $\mathrm{H} 2 \mathrm{O} 2$ droplets and examination of effective species. In: 15th International Symposium on Plasma Chemistry, 20012001 Orleans (France). 743-750. 
Yang, L. Q., Chen, J. R. \& Gao, J. L. 2009. Low temperature argon plasma sterilization effect on Pseudomonas aeruginosa and its mechanisms. Journal of Electrostatics, 67, 646-651.

Yasuda, H., Hashimoto, M., Rahman, M. M., Takashima, K. \& Mizuno, A. 2008. States of biological components in bacteria and bacteriophages during inactivation by atmospheric dielectric barrier discharges. Plasma Processes and Polymers, 5, 615621. 


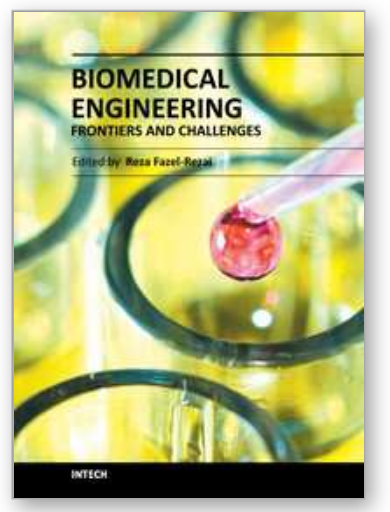

\author{
Biomedical Engineering - Frontiers and Challenges \\ Edited by Prof. Reza Fazel
}

ISBN 978-953-307-309-5

Hard cover, 374 pages

Publisher InTech

Published online 01, August, 2011

Published in print edition August, 2011

In all different areas in biomedical engineering, the ultimate objectives in research and education are to improve the quality life, reduce the impact of disease on the everyday life of individuals, and provide an appropriate infrastructure to promote and enhance the interaction of biomedical engineering researchers. This book is prepared in two volumes to introduce recent advances in different areas of biomedical engineering such as biomaterials, cellular engineering, biomedical devices, nanotechnology, and biomechanics. It is hoped that both of the volumes will bring more awareness about the biomedical engineering field and help in completing or establishing new research areas in biomedical engineering.

\title{
How to reference
}

In order to correctly reference this scholarly work, feel free to copy and paste the following:

R. Morent and N. De Geyter (2011). Inactivation of Bacteria by Non-Thermal Plasmas, Biomedical Engineering - Frontiers and Challenges, Prof. Reza Fazel (Ed.), ISBN: 978-953-307-309-5, InTech, Available from: http://www.intechopen.com/books/biomedical-engineering-frontiers-and-challenges/inactivation-of-bacteria-bynon-thermal-plasmas

\section{INTECH}

open science | open minds

\section{InTech Europe}

University Campus STeP Ri Slavka Krautzeka 83/A 51000 Rijeka, Croatia Phone: +385 (51) 770447 Fax: +385 (51) 686166 www.intechopen.com

\section{InTech China}

Unit 405, Office Block, Hotel Equatorial Shanghai No.65, Yan An Road (West), Shanghai, 200040, China 中国上海市延安西路65号上海国际贵都大饭店办公楼405单元 Phone: +86-21-62489820

Fax: +86-21-62489821 
(C) 2011 The Author(s). Licensee IntechOpen. This chapter is distributed under the terms of the Creative Commons Attribution-NonCommercialShareAlike-3.0 License, which permits use, distribution and reproduction for non-commercial purposes, provided the original is properly cited and derivative works building on this content are distributed under the same license. 